\title{
Genome-wide analysis of alternative splicing in Volvox carteri
}

\author{
Arash Kianianmomeni ${ }^{*^{*}}$, Cheng Soon Ong², Gunnar Rätsch ${ }^{3}$ and Armin Hallmann ${ }^{1 *}$
}

\begin{abstract}
Background: Alternative splicing is an essential mechanism for increasing transcriptome and proteome diversity in eukaryotes. Particularly in multicellular eukaryotes, this mechanism is involved in the regulation of developmental and physiological processes like growth, differentiation and signal transduction.

Results: Here we report the genome-wide analysis of alternative splicing in the multicellular green alga Volvox carteri. The bioinformatic analysis of 132,038 expressed sequence tags (ESTs) identified 580 alternative splicing events in a total of 426 genes. The predominant type of alternative splicing in Volvox is intron retention (46.5\%) followed by alternative $5^{\prime}(17.9 \%)$ and $3^{\prime}(21.9 \%)$ splice sites and exon skipping (9.5\%). Our analysis shows that in Volvox at least $\sim 2.9 \%$ of the intron-containing genes are subject to alternative splicing. Considering the total number of sequenced ESTs, the Volvox genome seems to provide more favorable conditions (e.g., regarding length and GC content of introns) for the occurrence of alternative splicing than the genome of its close unicellular relative Chlamydomonas. Moreover, many randomly chosen alternatively spliced genes of Volvox do not show alternative splicing in Chlamydomonas. Since the Volvox genome contains about the same number of protein-coding genes as the Chlamydomonas genome ( 14,500 protein-coding genes), we assumed that alternative splicing may play a key role in generation of genomic diversity, which is required to evolve from a simple one-cell ancestor to a multicellular organism with differentiated cell types (Mol Biol Evol 31:1402-1413, 2014). To confirm the alternative splicing events identified by bioinformatic analysis, several genes with different types of alternatively splicing have been selected followed by experimental verification of the predicted splice variants by RT-PCR.

Conclusions: The results show that our approach for prediction of alternative splicing events in Volvox was accurate and reliable. Moreover, quantitative real-time RT-PCR appears to be useful in Volvox for analyses of relationships between the appearance of specific alternative splicing variants and different kinds of physiological, metabolic and developmental processes as well as responses to environmental changes.
\end{abstract}

Keywords: Bioinformatics, Differential splicing, EST analysis, Green algae, Lower eukaryotes, Quantitative real-time RT-PCR, Transcriptome

\section{Background}

Alternative splicing of precursor messenger RNA (premRNA) is an important post-transcriptional regulatory mechanism that enhances the transcriptome plasticity and proteome diversity. Alternative splicing produces multiple transcripts from a single gene by varying the selection of the include/exclude regions. The different splicing products of a single gene produce different protein isoforms with different functions and effects [1-10].

\footnotetext{
*Correspondence: kianian@uni-bielefeld.de; armin.hallmann@gmx.de 'Department of Cellular and Developmental Biology of Plants, University of Bielefeld, Universitätsstr. 25, D-33615 Bielefeld, Germany

Full list of author information is available at the end of the article
}

Alternative splicing can also introduce premature stop codons, which cause down-regulation of expression of the corresponding gene by nonsense-mediated decay (NMD) of mRNA [11].

The five basic types of alternative splicing are as follows: 1) exon skipping, if an exon is either included in or excluded from the pre-mRNA; 2) intron retention, when an intron is either retained or excised from the pre-mRNA; 3) alternative $5^{\prime}$ splice sites and 4) alternative 3 ' splices site allow the extension or shortening of a particular exon, depending on the use of a proximal or distal $5^{\prime}$ and $3^{\prime}$ splice site, respectively; 5) mutually exclusive exons occur when two or more adjacent cassette 
exons are spliced such that only one of them is included at a time in the mRNA $[2,5,12]$.

Alternative splicing events are not rare, but quite common in eukaryotes. In human, $~ 95 \%$ of all introncontaining genes are alternatively spliced, $\sim 60 \%$ in Drosophila melanogaster, $25 \%$ in Caenorhabditis elegans and $\sim 61 \%$ in Arabidopsis thaliana (hereafter Arabidopsis) [13-21]. The real percentages might even be higher than reported, because they correlate with the number of sequenced ESTs. An increased number of sequenced ESTs frequently reveal additional alternative splicing events because more and more rare splicing variants from genes with low expression become sequenced. For Arabidopsis the reported percentage of alternatively spliced genes increased dramatically within a decade: it was $1.2 \%$ in 2003 [22], $11.6 \%$ in 2004 [23], more than $30 \%$ in 2006 [24], 42\% in 2010 [18] and 61\% in 2012 [19].

In Arabidopsis, the most frequent alternative splicing variant is intron retention ( 40\%) $[18,19]$. Most alternative splicing events in Arabidopsis, i.e. 78.4\%, occur in the coding region and about $50 \%$ of which produce a premature termination codon that is a potential target for NMD [5,25]. In addition, $15.2 \%$ of all alternative splicing events occur in the $5^{\prime}$-untranslated region (UTR) and $6.4 \%$ in the $3^{\prime}$ UTR [5]. In humans, the allocation is quite different from Arabidopsis: the most common alternative splicing variant is exon skipping (42-58\%), whereas intron retention forms only a small fraction (5-9\%) of all alternative splicing events $[5,26]$.

Two main factors that affect the occurrence of alternative splicing are intron lengths and the nucleotide composition of the introns [27]. Intronic nucleotide composition has been shown to affect splicing efficiency of intron retention [10,28-30]. Compared to the average length of human introns, which is 3365 bp, Arabidopsis introns are much shorter and show an average length of only $170 \mathrm{bp}[31,32]$. In human introns the AT content is only $51.9 \%$ [32], while plant introns show a high AT content: in Arabidopsis it is 67\% and in rice it is $73 \%[5,33,34]$. Moreover, the nucleotide composition of plant introns is also different between dicots and monocots. In rice, for example, the introns are longer and have a higher GC content than in Arabidopsis, which might be an indication for a different impact of alternative splicing in these organisms [27,35-37].

Alternative splicing produces protein isoforms that differ from each other with regard to localization, enzymatic activity, signaling effects and protein stability [2-5]. In plants, alternative splicing was shown to be involved in signal transduction and timing of flowering [5]. Alternative splicing can also act as a gene regulatory mechanism during developmental processes or in response to environmental conditions [2-6,8,9]. Various biotic and abiotic stress factors are known to influence alternative splicing [4,6,38-41]. Relevant abiotic stress factors are heavy metals, cold and heat. For example, the splicing of polyubiquitin and $h s p 70$ mRNAs in maize is affected by a heat shock $[42,43]$. Biotic stress factors that influence alternative splicing are viral and bacterial pathogens $[5,44,45]$. Plants even seem to regulate their transcriptome post-transcriptionally in response to quickly changing environmental conditions and pathogen attacks by using alternative splicing mechanisms [39,46,47].

Like in higher plants and animals, alternative splicing also is a common mechanism for increasing transcriptome diversity in much simpler organisms like algae. Previous studies in volvocine green algae, which include unicellular forms like Chlamydomonas reinhardtii (hereafter Chlamydomonas) to colonial and multicellular forms with increasing complexity like Volvox carteri (hereafter Volvox), revealed a number of genes that undergo alternative splicing. Examples include algal-CAM [48] and RBR1/mat3 [49,50] in Volvox and Cop1 [51] and CGE1 [52] in Chlamydomonas. A recent study about alternative splicing in Chlamydomonas indicates that about 3\% of all genes in Chlamydomonas undergo alternative splicing [53], which is much lower than recent reports from higher plants (e.g., 61\% in Arabidopsis; based on the analysis of 116 million paired-end RNA-seq reads of a normalized cDNA library) $[18,19]$. The analysis of a large EST dataset of Chlamydomonas resulted in 498 EST clusters that show 611 alternative splicing events [53]. The results indicated that $11.6 \%$ of the alternative splicing events in Chlamydomonas (based on the analysis of 252,484 ESTs) are alternative $5^{\prime}$ splice sites, $25.8 \%$ are alternative $3^{\prime}$ splice sites, $0.7 \%$ show both alternative $5^{\prime}$ and $3^{\prime}$ splice sites and $11.9 \%$ show exon skipping. Like in Arabidopsis, the most frequent alternative splicing event in Chlamydomonas is intron retention, which accounts for $50 \%$ of all events [53].

Based on molecular-phylogenetic studies, Volvox and Chlamydomonas probably diverged $\sim 200$ million years ago from a common unicellular ancestor [54]. On the time-scales of evolution, the transition from unicellular to multicellular life in Volvox is thus a quite recent occurrence when compared to other shifts to multicellularity. Other transitions to multicellularity, such as the ones that gave rise to plants and animals, occurred deep in the past, approaching a billion years ago $[55,56]$. The evolution of multicellular live in volvocine algae required several developmental traits including asymmetric cell division and embryonic morphogenesis. Most probably, the first multicellular volvocine algae were just small colonial organisms (like Gonium) without differentiated cells. Later size, cell number and overall complexity increased and a tendency to cell differentiation evolved (like in Eudorina and Pleodorina). Finally, even a complete division of labor between 
somatic cells and germ cells developed (like in Volvox) [57]. Comparative analyses of the Volvox and Chlamydomonas genomes revealed that the overall sequence divergence between these organisms is comparable to that between human and chicken (which diverged $~ 310$ million years ago) and Arabidopsis and poplar (which diverged $\sim 110$ million years ago). Moreover, despite conserved synteny between the genomes, Volvox and Chlamyomdonas show higher rates of genomic rearrangement than vertebrates and eudicots do [58]. The nuclear genome of Chlamydomonas is $118 \mathrm{Mbp}$ in size and that of its multicellular relative Volvox is composed of $138 \mathrm{Mbp}$. The larger genome of Volvox ( 17\% larger) is attributed to its higher content of transposons and repetitive DNA [58,59] because both species have almost identical protein-coding potentials, i.e., 14,516 and 14,520 protein-coding genes in Chlamydomonas and Volvox, respectively. Only a few gene families, i.e., the pherophorin genes, the VMP genes (Volvox matrix metalloproteases) and the cyclin-D related genes have more members in Volvox than in Chlamydomonas [58]. This suggests that the transition from a unicellular, Chlamydomonas-like ancestor to multicellular Volvox did not take major changes in gene content $[58,60]$ but mainly alterations in the mechanisms of genetic regulation. Thus, development of organismal complexity might be mainly caused by evolutionary innovations of preexisting proteins (e.g., transcription factors) and their binding sites, inventions of noncoding RNAs, innovations in the mechanism of alternative splicing and increase of alternative splicing events [58,61-64]. Alternative splicing can produce different protein isoforms from a single gene, which has produced only a single protein in an ancestor; in this way, diversity increases. Together with differences in selection pressures within a population, appearance or changes in alternative splicing can lead to speciation.

Interestingly, two key factors that affect the splicing mechanism are different between the genomes of Chlamydomonas and Volvox: the intron length and the nucleotide composition. With an average length of $491 \mathrm{bp}$, the introns of Volvox are clearly larger than Chlamydomonas introns, which span only $371 \mathrm{bp}$ on average [58] (Additional file 1: Table S1). Bioinformatic analyses showed that exons flanked by longer introns are more frequently subject to alternative splicing events than exons flanked by short introns [65,66]. Furthermore, the genome of Volvox shows a lower GC content (56\%) than the genome of Chlamydomonas (64\%) [58,59], which might cause differences between the two species in alternative splicing $[27,35]$. Based on these two key differences between both genomes, a detailed investigation of alternative splicing may reveal new insights into the gene regulation mechanisms that have been required for the evolutionary transition from unicellular Chlamydomonas to multicellular Volvox, while the number of genes remained about the same during this transition.

Here we report the analysis of alternative splicing in the multicellular green alga Volvox. After bioinformatic analysis of 132,038 ESTs, we identified 580 alternative splicing events corresponding to 426 genes. We show the distribution of the different types of alternative splicing events in Volvox and compare it with other species. To confirm our bioinformatic results, several alternatively spliced genes have been selected as representatives for experimental verification. After confirmation of alternative splicing variants by reverse transcription polymerase chain reaction (RT-PCR), the relative expression level of each splice variant was determined using quantitative real-time RT-PCR.

Our results indicate that alternative splicing is a widespread process for generating protein isoform diversity in Volvox, which suggests an important role of alternative splicing for expansion of organismal complexity during evolution of multicellularity and cell differentiation in volvocine algae.

\section{Results}

\section{Genomic mapping of ESTs}

The genome-wide analysis of alternative splicing in Volvox and its comparison with both a closely related unicellular alga (Chlamydomonas) and a more distantly related higher plant (Arabidopsis) required both extensive genomic and EST sequence data. These data were obtained from the corresponding databases of Volvox [58], Chlamydomonas [59] and Arabidopsis [31] (see Methods). The data sets of the three species were treated in the same way to provide the necessary comparability.

All available ESTs of the three species were aligned to the corresponding genomic contigs and genome sequences using BLAT, a BLAST-like alignment tool [67]. Only the best alignment was used to avoid double counting of paralogs. EST sequences with less than 95\% identity to any sequence in the corresponding genome were removed from further analysis. The resulting alignments were then clustered by their genomic location. In this process a cluster arises from the set of all ESTs, which overlap at a given genomic location.

Subsequently, the splice site consensus sequences were identified for all splicing events. The vast majority of introns in protein-coding genes of Volvox and of any other previously investigated eukaryote are canonical, which means that they have a GT dinucleotide at their $5^{\prime}$ end and an AG dinucleotide their 3' end [68]. Only about 1$2 \%$ of the introns are non-canonical. To compensate for artefacts that may occur in further analysis, we omitted alternative splicing events that involved introns with noncanonical splice site dinucleotides (i.e., not GT/AG).

Then, alternative splicing graphs of potential splice variants were constructed for each cluster in the three 
genomes. An intron was constructed in a given splice graph when there was EST evidence of a transcript with canonical splice sites.

A representative sample of one alternative splicing locus out of 6,925 loci in Volvox is shown in Figure 1. At the 6,925 loci we identified 31,885 exons. This gives an average of 4.6 exons per locus.

\section{Alternative splicing analysis and abundance of splicing events}

After genomic mapping of all available ESTs, we identified the alternatively spliced isoforms for each locus in Volvox, Chlamydomonas and Arabidopsis. Isoforms with alternative transcription starts or ends were not considered further in this paper, because we focus here on alternative splicing events. The alternatively spliced isoforms were divided into four major groups of events: exon skipping, intron retention, alternative $5^{\prime}$ and alternative $3^{\prime}$ splicing. In addition, there were instances of more complex splice forms, which were not covered by the above four simple alternative splicing events. To obtain splicing events with a high quality, we complement our predictions by a quality value to penalize the spurious events with poor EST support.

The bioinformatic analysis identified 580 alternative splicing events in Volvox in a total of 426 genes. Thus, about $2.9 \%$ of all $\sim 14,500$ protein-coding Volvox genes are subject to alternative splicing. This percentage is more similar to the one observed in higher plants than to that in the closely related unicellular relative Chlamydomonas; considering the number of analyzed ESTs.

The analysis of the different types of alternative splicing revealed that $9.5 \%$ of all alternative splicing events show exon skipping in Volvox, $46.5 \%$ show intron retention, $17.9 \%$ alternative $5^{\prime}$ splice sites and $21.9 \%$ alternative 3 ' splice sites (Figure 2A). Thus, the predominant

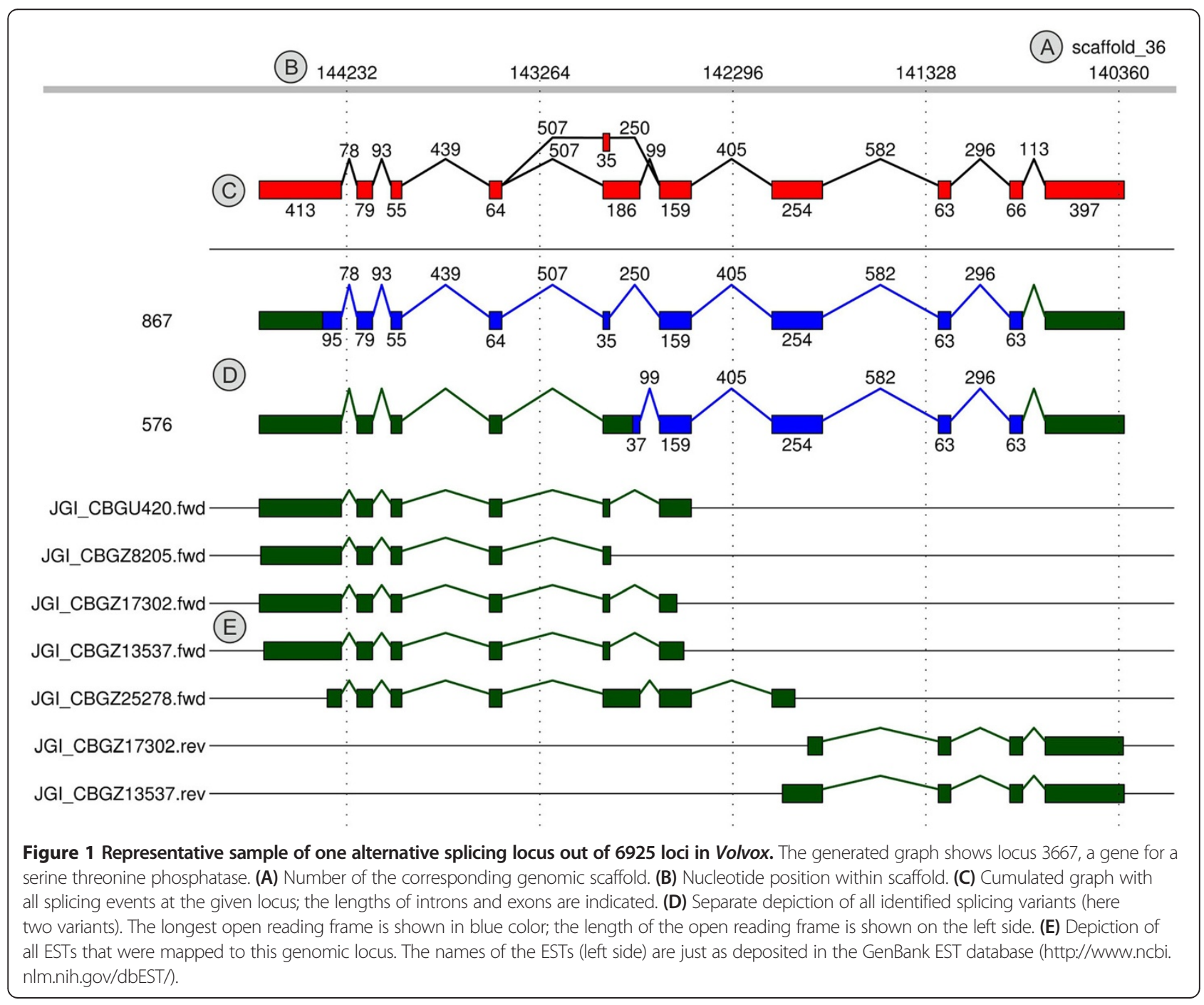



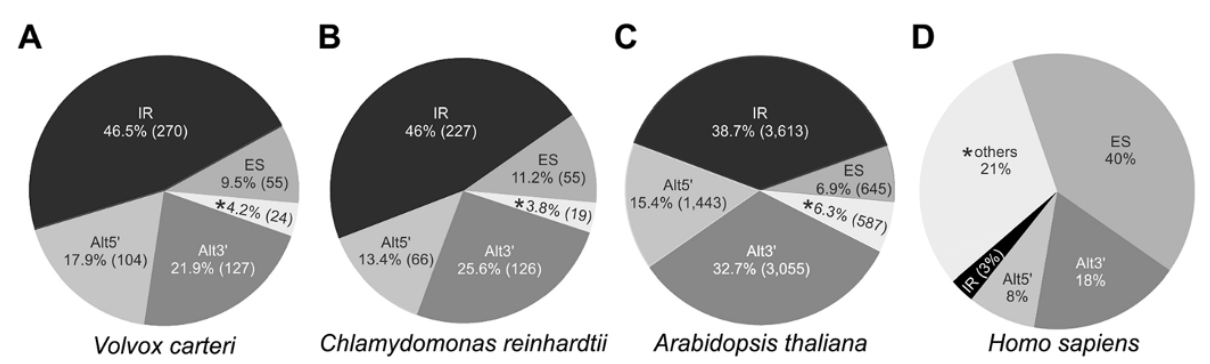

Figure 2 Distribution of the different types of alternative splicing events. The percentage and total number (in parenthesis) of splicing events is shown for each type of alternative splicing, i.e., intron retention (IR), exon skipping (ES), alternative $5^{\prime}$ splice site (Alt5') and alternative $3^{\prime}$ splice site (Alt3'). Asterisks $\left(^{*}\right)$ indicate the percentage of other, more complex alternative splicing types. The distribution is given for the species Volvox (A), Chlamydomonas (B), Arabidopsis (C) and human (D). The total number of alternative splicing events is 580 in Volvox, 493 in Chlamydomonas and 9,343 in Arabidopsis.

type of alternative splicing in Volvox is intron retention followed by alternative $3^{\prime}$ splice sites, alternative $5^{\prime}$ splice sites and exon skipping.

In the closely related alga Chlamydomonas, the intron retention also is the most common type of alternative splicing (46\%), followed by alternative 3' splice sites (25.6\%), alternative $5^{\prime}$ splice sites (13.4\%) and exon skipping (11.2\%) (Figure 2B). In Arabidopsis, the prevalence of different alternative splicing types shows the same distribution as in Volvox and Chlamydomonas, i.e. the percentage decreases in the following order: intron retention $>$ alternative $3^{\prime}$ splice sites $>$ alternative $5^{\prime}$ splice sites $>$ exon skipping (Figure 2C). In contrast to non-plant model organisms like human (Figure 2D), exon skipping is the rarest simple form of alternative splicing in all of the three investigated species (Figures 2A-C).

\section{Localization of alternative splicing events}

In Volvox, the majority of all alternative splicing events (66.7\%) affect the coding regions. Another $33.3 \%$ occur within non-coding regions (14.8\% in $5^{\prime}$ UTRs and $18.5 \%$ in 3' UTRs) (Figure 3A). The results from Volvox were again compared with the genome and EST data of Chlamydomonas and Arabidopsis [31,59], which were treated in the same way as the data from Volvox (see
Methods). In Chlamydomonas, $10.8 \%$ of the alternative splicing events were detected in $5^{\prime}$ UTRs and $10.1 \%$ in 3' UTRs (Figure 3B). In Arabidopsis, 12.8\% of the alternative splicing events were localized in $5^{\prime}$ UTRs and $15.7 \%$ in 3' UTRs (Figure 3C). In both organisms, the majority of alternative splicing events occur within the coding region, just as observed in Volvox. More precisely, it was $79.1 \%$ in Chlamydomonas and $71.5 \%$ in Arabidopsis (Figures 3B and 3C).

\section{Experimental verification of alternative splicing events}

To validate the quality of both the used ESTs and our bioinformatic analysis, ten sample genes with identified alternative splicing events were selected for experimental verification by RT-PCR and quantitative real time RTPCR (Additional file 1: Table S2). The decisive factor in the choice of a sample gene to be tested was the potential modification of protein domains or protein sequence motifs by alternative splicing. Strong EST support, however, was not relevant for our selection. As a consequence of this approach, for some of the selected sample genes, like the genes for the mitochondrial translation elongation factor $\mathrm{Tu}(e f g 8)$ and the selenocysteine-specific elongation factor (selEFf) [50], only one supporting EST for a given alternative splicing variant was available. By contrast, for
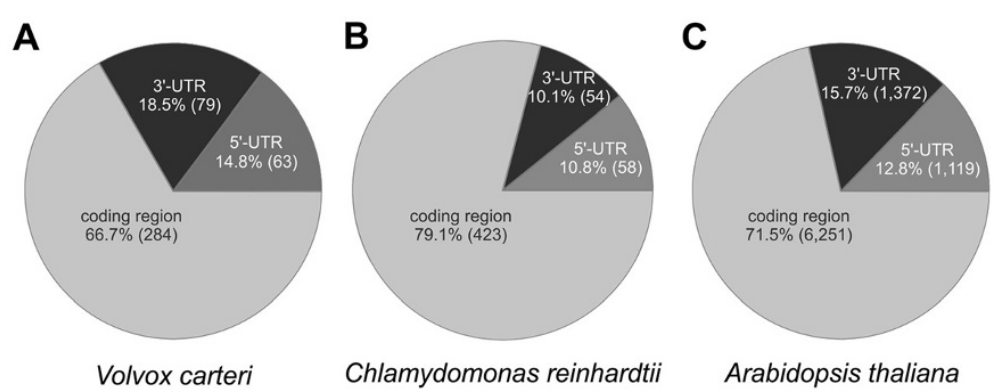

Figure 3 Localization of alternative splicing events in the mRNAs. In the species Volvox (A), Chlamydomonas (B) and Arabidopsis (C) each mRNA was divided into coding region, 5' UTR or $3^{\prime}$ UTR. The percentage and total number (in parenthesis) of splicing events is given for each of these mRNA regions. The splicing events totaled together 426 events in Volvox, 535 in Chlamydomonas and 8,742 in Arabidopsis. 
other genes, like the gene for the oxygen evolving enhancer protein 1 (ooe1), more than one hundred ESTs existed (data not shown).

The statistical evaluation of the data obtained from our bioinformatic analysis of alternative splicing indicates that splice variants of genes that show exon skipping lead more frequently to changes in protein properties (like protein localization and activity) than genes showing any other type of alternative splicing (data not shown). For that reason, the following seven sample genes with exon skipping and (putative) differences in the properties of the protein variants were selected: clpr2 (chloroplast Clp protease), efg8 (mitochondrial translation elongation factor $\mathrm{Tu}$ ), hyd2 (iron hydrogenase), lsg2 (matrix metalloproteinase), mgmt (6-O-methylguanine DNA methyltransferase), nrnp1 (nuclear ribonucleoprotein) and selEFf (selenocysteine-specific elongation factor) (Figure 4 and Additional file 1: Table S2). Of particular interest was the experimental verification of the splicing products of efg 8 and selEFf because of their uncommon gene structures with extremely long introns, which were $10772 \mathrm{bp}$ (efg8) and $16365 \mathrm{bp}$ (selEFf) in length (Figure 4).

In addition to exon skipping, we chose three further sample genes with other types of alternative splicing, which also lead to changes in protein properties. The selected genes were cyn23 (cyclophilin-type peptidyl-prolyl cis-trans isomerase), which shows alternative splicing via mutually exclusive exons, oee1 (oxygen evolving enhancer protein 1), which is an example for intron retention, and ppi1 (protein phosphatase inhibitor), which produces protein isoforms through alternative $5^{\prime}$ splice sites (Figure 4 and Additional file 1: Table S2).

To allow for a distinction of the different splice variants of a given gene, we named the variants "first" and "second" splice variant. More precisely, the variant that shows an exon-intron structure identical or similar to a gene structure predicted as part of the Volvox genome project [58] or in a database entry (Additional file 1: Table S2) was called "first splice variant" and another splice variant was called "second splice variant".

\section{Verification of exon skipping}

The first of the seven sample genes with exon skipping was clpr 2 . This gene codes for a highly conserved, ATPdependent serine protease [69], which shows $86 \%$ identity to Chlamydomonas CLPR2 in an overlap of 285 amino acid residues [70]. Clp proteases are involved in many cellular and extracellular processes such as degradation of misfolded proteins, cell signaling and removing of short-lived regulatory proteins $[69,71]$. The clpr2 gene of Volvox is 2,599 bp in length (from start to stop codon) and includes 8 exons and 7 introns (Figure 4A, Additional file 1: Table S2). In the second splice variant of clpr2, exon five that is $135 \mathrm{bp}$ in length is excluded from the mRNA by exon skipping (Figure 4A). The first splice variant encodes a 284-residue polypeptide whereas the second splicing variant encodes a 239-residue polypeptide (Additional file 1: Figure S1A, Additional file 1: Table S2). The structure of the ClpP protein isoform encoded by the second splice variant probably differs from the reported protein structure of ClpP [72], which is encoded by the first splice variant (Additional file 1: Figure S1B). The conserved amino acid residues F100, N111, Y119 and L120, which are involved in the $\alpha / \beta$ type fold of the protein [72], are lacking in the second protein variant of clpr2 (Additional file 1: Figure S1A). Both splice variants of clpr 2 have been amplified by RTPCR to confirm the results of the bioinformatic analysis. For it, total RNA was isolated from synchronously growing female Volvox cultures at the stage of hatching. Pairs of primers were established to amplify each splice variant separately. For amplification of the first splice variant of clpr2, one primer, ON15266, resides on exon 5, which is lacking in the mRNA of the second splice variant; the second primer is ON15265 on exon 4 (Figure 4A and Additional file 1: Table S3). For verification of the second splice variant, one primer, ON15267, only binds to the exon-exon junction of exons 4 and 6, which emerges only after removal of a $659 \mathrm{bp}$ fragment between exon 4 and exon 6 by splicing; the second primer was ON15265 on exon 4 (Figure 4A and Additional file 1: Table S3). A 134-bp cDNA fragment was predicted for variant 1 and a 117-bp fragment for variant 2; the RT-PCR yielded fragments of the expected sizes (Figure 5A, Additional file 1: Table S3). It was also possible to amplify both variants in one and the same reaction using only a single pair of primers (ON15265 and ON15371, Figure 4A and in Additional file 1: Table S3). Fragments of 278 bp (variant 1) and $143 \mathrm{bp}$ (variant 2) were expected and actually obtained in the RT-PCR (Figure 6 and Additional file 1: Table S3); it should be mentioned that in addition to the correct fragments, some non-specific side products were amplified (Figure 6). Subsequently, the relative expression levels of both splice variants were measured by quantitative real-time RT-PCR, which is a sensitive method for analyzing relative expression levels of alternative splicing variants [49,73-75]. As a reference gene for the quantitative realtime RT-PCRs the actin gene was used. The actin gene already has been used in previous studies as a reference in RT-PCR and quantitative real-time RT-PCR expression analyses [49,76-78]. The primer pairs ON15265/ON15266 and ON15265/ON15267 were used to amplify the first and the second splice variant separately. Both primer pairs did not produce any non-specific fragments during RT-PCR reactions and the fragment sizes were between 100 and $200 \mathrm{bp}$ which is the optimal fragment size for quantitative real-time RT-PCR [79]. The expression levels were 


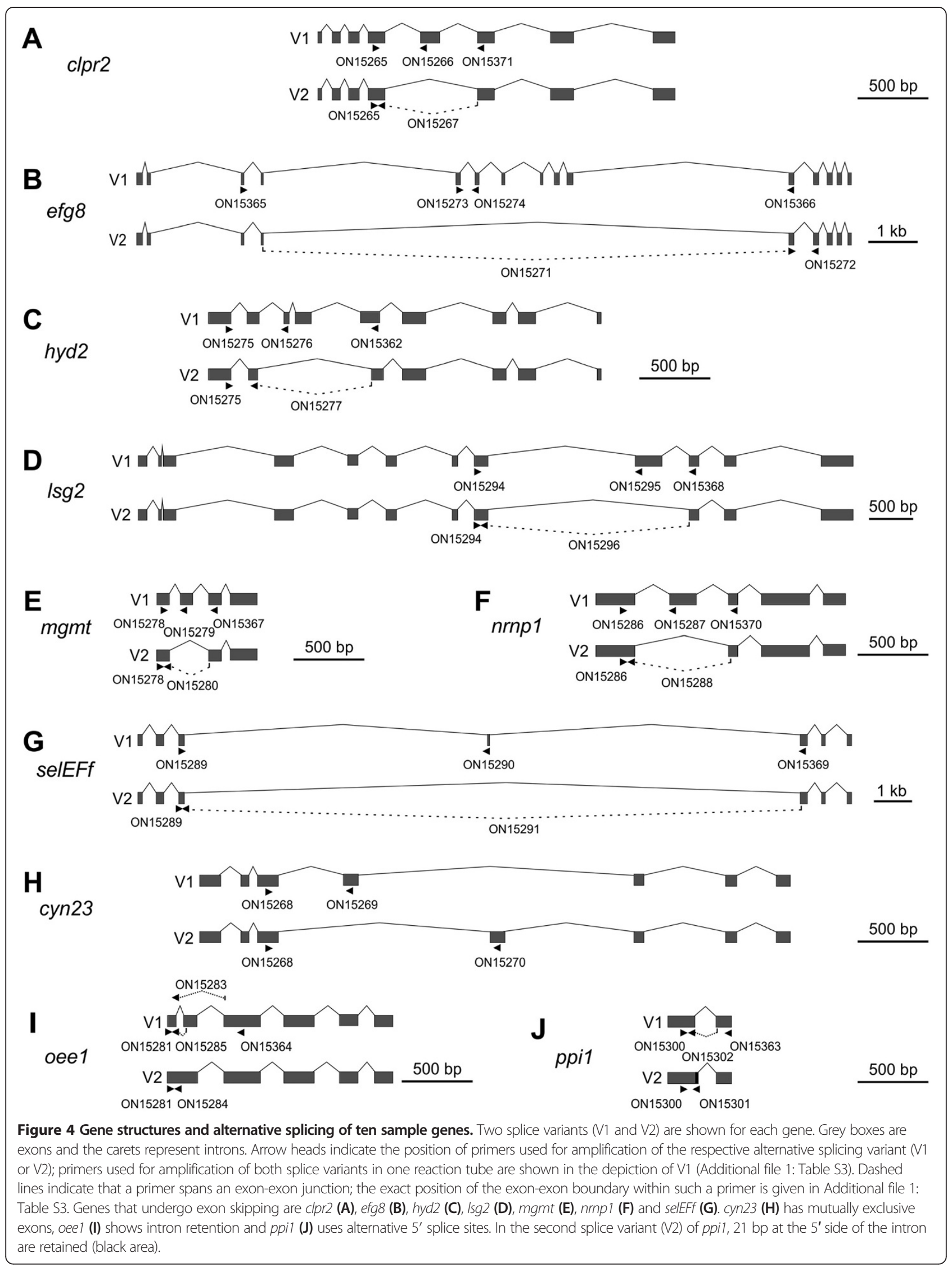



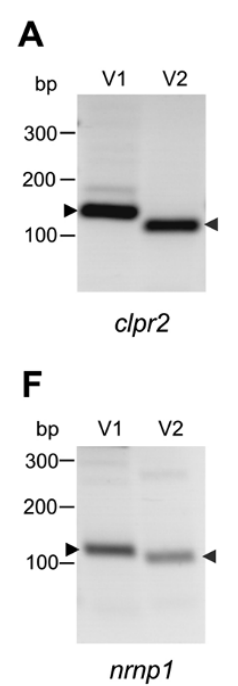
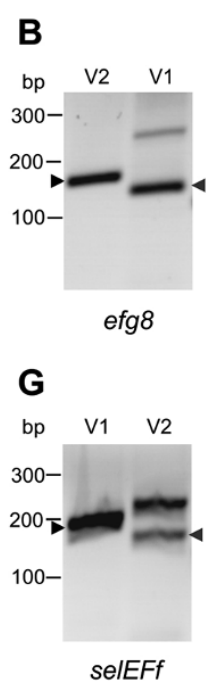
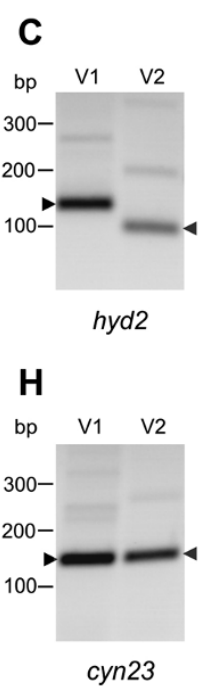
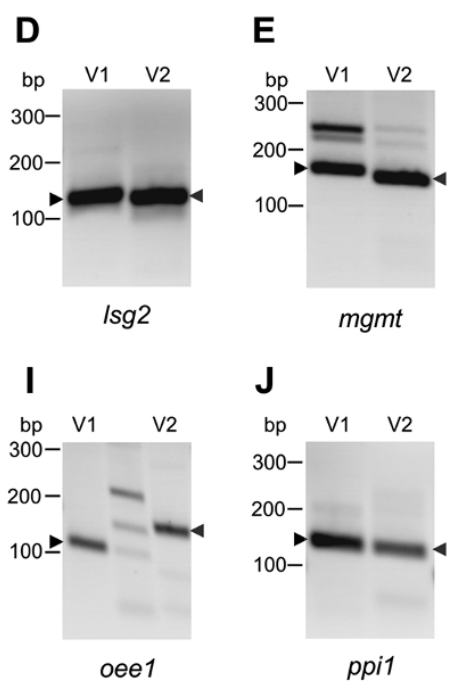

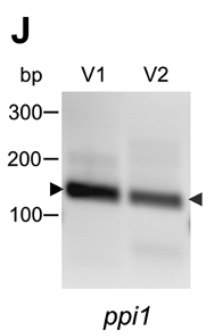

Figure 5 RT-PCR amplification of characteristic fragments of the different splice variants. The investigated sample genes with alternative splicing were clpr2 (A), efg8 (B), hyd2 (C), Isg2 (D), mgmt (E), nrnp1 (F), selEFf (G), cyn23 (H), oeel (I) and ppi1 (J). Primers were designed to amplify a characteristic fragment of each alternative splicing variant specifically (Figure 4 and Additional file 1: Table S3). The amplicons of the first (V1) and second (V2) alternative splicing variants have been cloned and sequenced. The expected lengths of fragments are given in Additional file 1: Table S3. DNA fragments that are consistent with the predictions are marked by arrowheads.

calculated using the $\Delta \Delta \mathrm{Ct}$-method as described previously [78] and the results are shown in Figure 7A. The expression of the first splice variant of clpr2 is $\sim 1.6$ fold less than actin and $\sim 35.8$ fold higher than the expression of the second splice variant (Figure 7A).

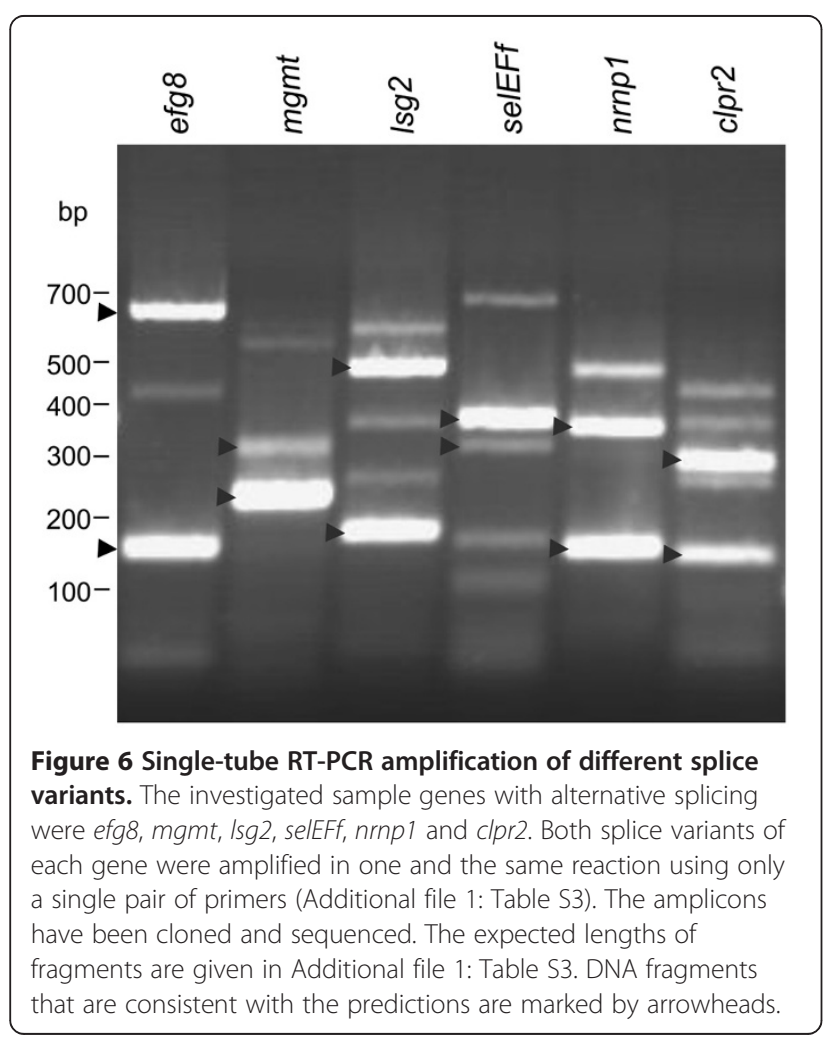

The second exon skipping candidate was efg8 (Figure 4B, Additional file 1: Table S2). This gene codes for the mitochondrial elongation factor EF-TU and it is localized at the mating type locus of Volvox [50]. EF-TU elongation factors belong to the large family of GTP-binding elongation factors [80]. The first splice variant of efg 8 encodes a polypeptide of 453 amino acid residues, including three elongation factor domains, i.e. EF-TU, EFTU-II and EFTU-III (Additional file 1: Figures S2A-B). All three domains are essential for the elongation phase in protein synthesis [81]. The first domain, EF-TU, is the catalytic domain, which is responsible for the binding to the guanine nucleotide [82]. The non-catalytic domains II and III show a beta-barrel structure with six anti-parallel strands, which appear to be tightly associated to the catalytic domain $[82,83]$. Interestingly, six exons are excluded in the second splice variant, which reduces the length of the mRNA by 510 nucleotides and the encoded polypeptide chain by 170 amino acid residues (Figure 4B, Additional file 1: Figure S2A). In the second variant, 139 amino acid residues of the catalytic EF-TU domain are lacking, which will in all likelihood affect the binding properties of the domain. Moreover, GTP-binding proteins usually have two conserved sequences with the consensus sequences Asn-Lys-x-Asp (residues 192 to 195 in the first variant) and Ser-Ala-Leu/Lys (residues 230 to 233 in the first variant), which are important for the binding to a guanine nucleotid [84]; both motives are lacking in the second variant (Additional file 1: Figure S2A). The first part of the EFTU-II domain also is absent in the second variant, which should cause altered binding properties and, thus, 


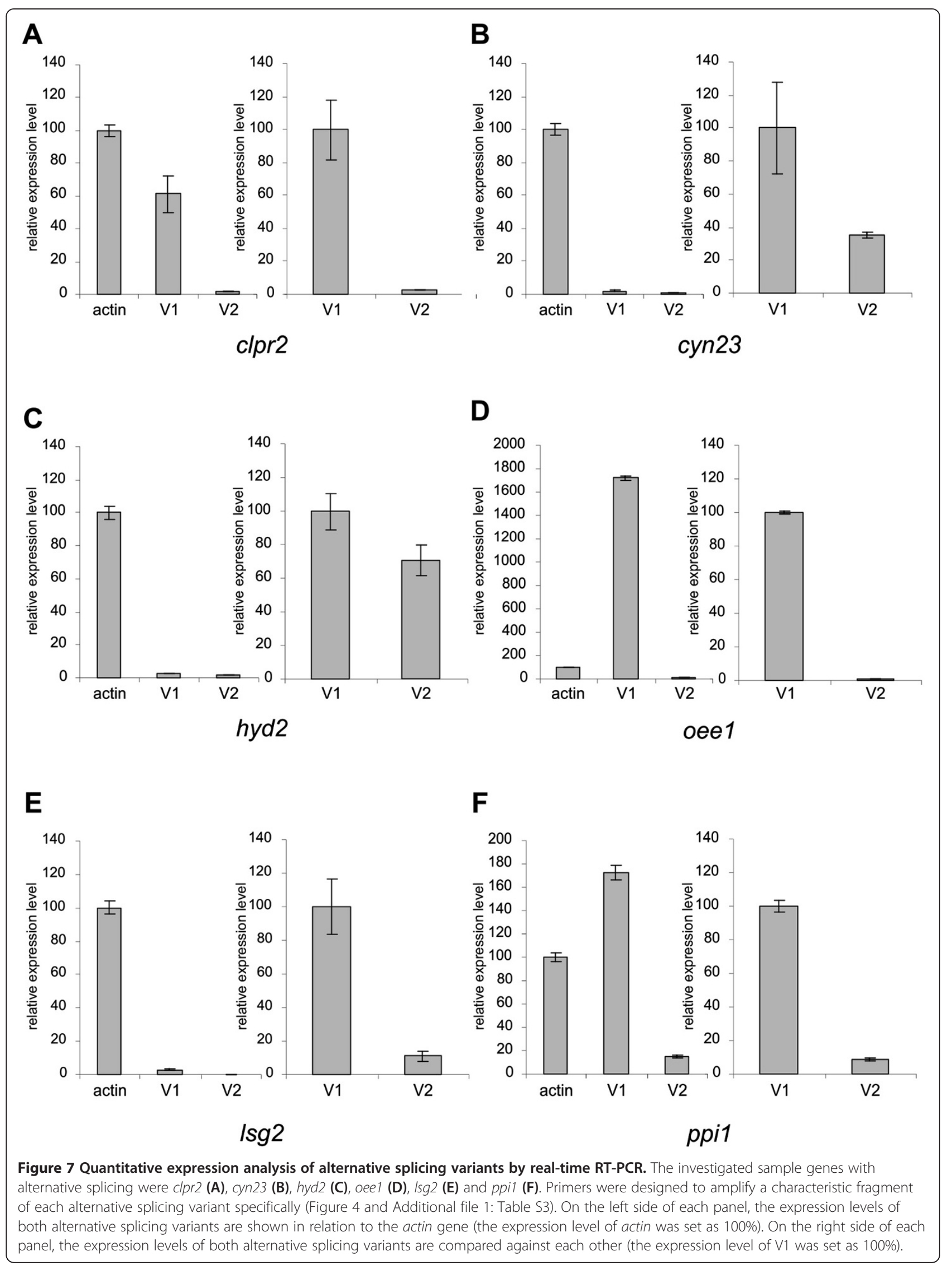


affect its activity in RNA translation [85,86]. For amplification of the first splice variant of efg 8 by RT-PCR, the primer ON15273 resides on exon 5 and primer ON15274 is located on exon 6; both exons are lacking in the mRNA of the second splice variant. For verification of the second splice variant, one primer, ON15271, only binds to the exon-exon junction of exons 4 and 11, which emerges only after removal of a large fragment (10772 bp) between exon 4 and exon 11 by splicing; the second primer was ON15272 on exon 12. A 151-bp cDNA fragment was predicted for variant 1 and a 176-bp fragment for variant 2; the RT-PCR yielded fragments of the expected sizes (Figure 5B, Additional file 1: Table S3). It was also possible to amplify both variants in one and the same reaction using only a single pair of primers (ON15365 and ON15366, Figure 4B and in Additional file 1: Table S3). Fragments of 664 bp (variant 1) and 154 bp (variant 2) were expected and actually obtained in the RT-PCR (Figure 6 and Additional file 1: Table S3). The relative expression levels of both splice variants of efg 8 could not be determined by quantitative real-time RT-PCR because non-specific side products defeated the analysis repeatedly (the same was true for mgmt, nrnp1 and selEFf).

The third sample gene was hyd2. This gene codes for an iron hydrogenase, which catalyzes the reversible conversion of molecular hydrogen to protons and electrons $[87,88]$ (Figure 4C, Additional file 1: Table S2). The first splice variant of $h y d 2$ encodes a polypeptide with a large Fe-only hydrogenase domain, which is 352 amino acid residues long (residues 82 to 434). In the second splice variant, 169 amino acid residues are lacking at the $\mathrm{N}$-terminal end of the polypeptide (Figure 4C, Additional file 1: Figure S3A), including 88 amino acid residues of the Fe-only hydrogenase domain $[89,90]$. The X-ray crystal structure of the Feonly hydrogenase from Clostridium pasteurianum could show that the amino acid residues 90 to 97 and 130 to 135 are essential to form $\beta$ sheets around the active site [91] (Additional file 1: Figure S3A). Lack of this part in the second splice variant should change the protein structure and, as a consequence, the enzyme characteristics. In contrast, the actual active site is present in both variants of the Fe-only hydrogenase [90] (Additional file 1: Figure S3A). There are three conserved protein sequence motifs in the active site of variant 1 , motif 1 (PMFTSCCPxW, residues 169 to 178), motif 2 (MPCxxKxxExxR, residues 228 to 239) and motif 3 (FxExMACxGxCV, residues 415 to 426), and variant 2 contains exactly the same motifs except for the very first amino acid residue of motif 1 . For amplification of the first splice variant of hyd2 by RT-PCR, one primer, ON15276, resides on exon 3, which is lacking in the mRNA of the second splice variant; the second primer was ON15276 on exon 1 (Figure 4C and Additional file 1: Table S3). For verification of the second splice variant, one primer, ON15277, only binds to the exon-exon junction of exons 2 and 5, which emerges only after removal of a 818 bp fragment between exon 2 and exon 5 by splicing; the second primer was ON15275 on exon 1 (Figure 4C and Additional file 1: Table S3). A 128-bp cDNA fragment was predicted for variant 1 and a 102-bp fragment for variant 2; the RT-PCR yielded fragments of the expected sizes (Figure 5C, Additional file 1: Table S3); the band of variant 2 showed a lower intensity than the band of variant 1 . It was not possible to amplify both variants of hyd2 in one and the same reaction, instead only one of both variants was amplified (the same was true for cyn23, oee1 and ppi1). However, the relative expression levels of both splice variants could be determined by quantitative real-time RTPCR. The expression of the first splice variant of hyd2 is only $\sim 1.5$ fold higher than the expression of the second splice variant (Figure 7C). Compared to actin, both splice variants are expressed at a very low level, i.e. hyd2 variants 1 and 2 account for only $2.4 \%$ and $1.7 \%$, respectively, of the actin expression level (Figure 7C).

The fourth exon skipping candidate was $l s g 2$. This Volvox gene codes for a matrix metalloproteinase; $l s g 2$ was shown to be expressed with an above-average rate during the late developmental stages in somatic cells [92] (Additional file 1: Table S2). Lsg2 (variant 1) shows $31 \%$ identity to the gamete lytic enzyme (GLE) of Chlamydomonas in an overlap of 537 amino acid residues. GLE of Chlamydomonas is a proteinase, which degrades cell walls of gametes during mating [93]. For enzymatic degradation, it contains a large peptidase M11 domain (amino acid residues 146 to 458 in variant 1, Additional file 1: Figure S4A) The M11 domain is conserved among several metalloproteinases including VMPs [94,95]. The typical HExxHxxGxxH motif, which contains four histidine residues for zinc binding in the active site of the enzyme [96] can be found in variant 1 of Lsg2 (amino acid residues 301 to 312, Additional file 1: Figure S4A). Another motif, which is believed to be responsible for the binding to calcium, is also conserved in variant 1 of Lsg2 (amino acid residues 500 to 512, Additional file 1: Figure S4A). In contrast, 103 amino acid residues of the peptidase M11 domain are lacking in the polypeptide encoded by the second splice variant, because exon nine (309 bp) is excluded by exon skipping (Figure 4D, Additional file 1: Figure S4A). For amplification of the first splice variant of $l s g 2$ by RT-PCR, one primer, ON15295, resides on exon 9 , which is lacking in the mRNA of the second splice variant; the second primer was ON15294 on exon 8 (Figure 4D and Additional file 1: Table S3). For verification of the second splice variant, one primer, ON15296, only binds to the exon-exon junction of exons 8 and 10, which emerges only after removal of a 2285 bp fragment between exon 8 and exon 10 by splicing; the second primer was ON15294 on exon 8 (Figure 4D and Additional file 1: Table S3). A 137-bp cDNA fragment was predicted for variant 1 and a 131-bp fragment for variant 2; 
the RT-PCR yielded fragments of the expected sizes (Figure 5D, Additional file 1: Table S3). It was also possible to amplify both variants in one and the same reaction using only a single pair of primers (ON15294 and ON15368, Figure 4D and Additional file 1: Table S3). Fragments of 482 bp (variant 1) and $173 \mathrm{bp}$ (variant 2) were expected and actually obtained in the RT-PCR (Figure 6 and Additional file 1: Table S3); it should be mentioned that in addition to the correct fragments, some non-specific side products were amplified (Figure 6). Quantitative real-time RT-PCR showed that both splice variants are expressed at a very low level in comparison to actin. However, the expression of the first splice variant of $l s g 2$ is $\sim 10$ fold higher than the expression of the second splice variant (Figure 7E).

The fifth sample gene was mgmt. This gene codes for a putative 6-O-methylguanine DNA methyltransferase (Additional file 1: Table S2). The O-6-methylguanine-DNA methyltransferase is essential for viability because it reverses DNA alkylation damage by removing the offending alkyl group [97-99]. The first splice variant of $m g m t$ encodes a polypeptide with 153 amino acid residues in length (Additional file 1: Table S2, Additional file 1: Figure S5A) and contains a DNA binding domain, which is 89 amino acid residues long [100] (Additional file 1: Figure $\mathrm{S} 5 \mathrm{~A}, \mathrm{~B})$. As a result of the exon skipping event, 29 residues are lacking in the DNA binding domain of the second variant (Figure 4E, Additional file 1: Figure S5A). Some of these 29 amino acid residues were previously shown to be involved in DNA binding [101]. For example, the tyrosine residue at position 44 of variant 1 (Y44, Additional file 1: Figure S5A) has been shown to be a key residue involved in recognition of the O6-alkylguanine lesion through a hydrogen bond with the N3 atom of the modified base [101,102]. Furthermore, the arginine residue at position 56 of variant 1 (R56, Additional file 1: Figure S5A) is necessary for the repair of base damage in duplex DNA [100]. The absence of these two amino acid residues most probably affects the binding characteristics of the second protein variant. For amplification of the first splice variant of $m g m t$ by RT-PCR, one primer, ON15279, resides on exon 2, which is lacking in the mRNA of the second splice variant; the second primer was ON15278 on exon 1 (Figure 4E and Additional file 1: Table S3). For verification of the second splice variant, one primer, ON15280, only binds to the exon-exon junction of exons 1 and 3, which emerges only after removal of a $276 \mathrm{bp}$ fragment between exon 1 and exon 3 by splicing; the second primer was ON15278 on exon 1 (Figure 4E and Additional file 1: Table S3). A 173-bp cDNA fragment was predicted for variant 1 and a 165-bp fragment for variant 2; the RT-PCR yielded fragments of the expected sizes (Figure 5E, Additional file 1: Table S3); in the PCR of variant 1 also two larger, non-specific side products were amplified, as verified by cloning and sequencing. It was also possible to amplify both variants in one and the same reaction using only a single pair of primers (ON15278 and ON15367, Figure 4E and Additional file 1: Table S3). Fragments of $310 \mathrm{bp}$ (variant 1) and $223 \mathrm{bp}$ (variant 2) were expected and actually obtained in the RT-PCR (Figure 6 and Additional file 1: Table S3); it should be mentioned that in addition to the correct fragments, a larger, non-specific side product was amplified (Figure 6).

The sixth exon skipping candidate was nrnp1. This Volvox gene codes for a polypeptide with two RNA recognition motif (RRM) domains, also known as RNA binding domains (RBDs). The RRM domain is by far the most abundant type of eukaryotic RNA-binding motif. This domain is involved in different cellular processes like mRNA and rRNA processing, RNA export and RNA stability [103-105]. The first splice variant of nrnp1 encodes a polypeptide with 344 amino acid residues; the RRMs are localized at amino acid residues 76 to 132 and 150 to 219 (Additional file 1: Table S2, Additional file 1: Figure S6A). The protein product of the second splice variant is 179 amino acid residues shorter than the first variant (Figure 4F and Additional file 1: Figure S6). In the second variant, the first RRM domain is lacking and the second RRM domain is truncated, i.e., 29 amino acid residues are lacking (Additional file 1: Figure S6A). The crystal structure analysis of the RRM domain previously showed that the first part of the domain is important for correct folding [106]. The complete elimination of the first RRM and the truncation of the second RRM domain most probably change the RNA binding capacity significantly in the second variant. For amplification of the first splice variant of nrnp1 by RTPCR, one primer, ON15287, resides on exon 2, which is lacking in the mRNA of the second splice variant; the second primer was ON15286 on exon 1 (Figure 4F and Additional file 1: Table S3). For verification of the second splice variant, one primer, ON15288, only binds to the exon-exon junction of exons 1 and 3, which emerges only after removal of a 542 bp fragment between exon 1 and exon 3 by splicing; the second primer was ON15286 on exon 1 (Figure 4F and Additional file 1: Table S3). A 116-bp cDNA fragment was predicted for variant 1 and a 107-bp fragment for variant 2; the RT-PCR yielded fragments of the expected sizes (Figure 5F, Additional file 1: Table S3). It was also possible to amplify both variants in one and the same reaction using only a single pair of primers (ON15286 and ON15370, Figure 4F and Additional file 1: Table S3). Fragments of $342 \mathrm{bp}$ (variant 1) and $152 \mathrm{bp}$ (variant 2) were expected and actually obtained in the RTPCR (Figure 6 and Additional file 1: Table S3); it should be mentioned that in addition to the correct fragments, a larger, non-specific side product was amplified (Figure 6).

The seventh and last exon skipping candidate was selEFf, which is localized at the mating type locus of Volvox [50] (Additional file 1: Table S2). This gene codes for a putative selenocysteine-specific elongation factor 
(selEFf). Such translation factors are necessary for the incorporation of selenocysteine into proteins; selEFfs probably replace EF-Tu for the insertion of selenocysteine directed by the UGA codon [107]. In the first splice variant of selEFf, a very short exon (exon 4, $56 \mathrm{bp}$ ) is flanked by two very large introns, 7,996 bp and 8,313 bp in length (Figure 4G). This exon is excluded from the second splice variant by exon skipping and thus, an intron of 16,365 bp is spliced out. This intron seems to be the largest intron reported so far in Volvox. The alternative splicing event in the second variant also introduces a premature stop codon into the open reading frame (Additional file 1: Figure S7A). Unfortunately, no information about the structure of selEFf proteins is available, but the elimination of 142 amino acid residues in the second splice variant means that the length of the polypeptide is almost halved relative to the first variant and this significant cut-off probably affects the structure and characteristics of this translation factor. For amplification of the first splice variant of selEFf by RT-PCR, one primer, ON15290, resides on exon 4, which is lacking in the mRNA of the second splice variant; the second primer was ON15289 on exon 3 (Figure 4G and Additional file 1: Table S3). For verification of the second splice variant, one primer, ON15291, only binds to the exon-exon junction of exons 3 and 5, which emerges only after removal of a $16365 \mathrm{bp}$ fragment between exon 3 and exon 5 by splicing; the second primer was ON15289 on exon 3 (Figure $4 \mathrm{G}$ and Additional file 1: Table S3). A 196-bp cDNA fragment was predicted for variant 1 and a 166-bp fragment for variant 2; the RT-PCR yielded fragments of the expected sizes (Figure 5G, Additional file 1: Table S3); in addition to the correct fragments, a larger, non-specific side product was amplified in the RT-PCR for the second variant. It was also possible to amplify both variants in one and the same reaction using only a single pair of primers (ON15289 and ON15369, Figure 4G and Additional file 1: Table S3). Fragments of $357 \mathrm{bp}$ (variant 1) and $301 \mathrm{bp}$ (variant 2) were expected and actually obtained in the RT-PCR (Figure 6 and Additional file 1: Table S3); in addition to the correct fragments, some nonspecific side products were amplified (Figure 6).

\section{Verification of mutually exclusive exons}

The sample gene for mutually exclusive exons was cyn23, which encodes a cyclophilin-related protein (Additional file 1: Table S2). Cyclophilins are ubiquitous proteins that belong to the family of peptidyl-prolyl cis/trans isomerases (PPIases) [108], also known as immunophilins. These immunophilins are proposed to function in protein folding, protein degradation, stress response, signal transduction and pre-mRNA splicing [109-113]. The cyn23 gene contains two alternate mutually exclusive exons, exons 4 and 5. Because both exons are 106 nucleotides in length (Figure 4H, Additional file 1: Figure S11), the number of amino acid residues of the two protein isoforms is identical. However, the two isoforms differ from each other at 13 amino acid positions: A125G, G127Y, G128D, N129D, K130P, G132S, A133G, R134A, V139I, E150Q, A152T, I153A and G155A (Additional file 1: Figure S8A). Some of these residues, like alanine at position 125 , have been reported to be part of the cyclosporin-binding site [114,115]. Moreover, exchange of amino acids between positions 116 and 155 by site-directed mutagenesis was shown to affect the binding properties of cyclophilins $[116,117]$. Therefore, the differences in amino acid sequence between the two isoforms might produce isoforms with different binding properties. For amplification of the first splice variant of cyn 23 by RT-PCR, one primer, ON15269, resides on exon 4 and the second primer is ON15268 on exon 3 (Figure $4 \mathrm{H}$ and Additional file 1: Table S3). For verification of the second splice variant, one primer, ON15270, resides on exon 5 and the second primer again was ON15268 on exon 3. A 145-bp cDNA fragment was predicted for variant 1 and a 146 -bp fragment for variant 2; the RT-PCR yielded fragments of the expected sizes (Figure $5 \mathrm{H}$, Additional file 1 : Table S3). Due to the almost identical fragment sizes and the resulting identical migration distances in the gel, both variants were not amplified in one and the same reaction. Quantitative real-time RT-PCR showed that both splice variants are expressed at a very low level in comparison to actin. However, the expression of the first splice variant of cyn 23 is $\sim 2.8$ fold higher than the expression of the second splice variant (Figure 7B).

\section{Verification of intron retention}

The candidate gene for verification of intron retention was oee1, which codes for a subunit of the oxygen evolving complex of photosystem II (Additional file 1: Table S2). Previously, it was demonstrated that oee1 is subject to germline-specific expression in Volvox $[118,119]$. The first splice variant of oee1 encodes a polypeptide of 297 amino acid residues (Additional file 1: Figure S9A, Additional file 1: Table S2), which shows $87 \%$ identity to OEE1 of Chlamydomonas in an overlap of 294 amino acid residues [120]. It includes a large manganese-stabilizing protein (MSP) domain (Additional file 1: Figure S9A, B), which is required for photosystem II assembly, stability and photoautotrophy [121]. In the second splice variant of oee1, the first intron (69 bp in length) is retained by alternative intron retention (Figure 4I), which potentially leads to an N-terminally truncated protein isoform with a shortened MPS domain (Additional file 1: Figure S9A,B).

For verification of the first splice variant of oee1 by RTPCR, one primer, ON15285, only binds to the exon-exon junction of exons 1 and 2, which emerges only after removal of intron 1 (69 bp) by splicing; the second primer was ON15281 on exon 1 (Figure 4I and Additional file 1: Table S3). For amplification of the second splice variant, 
one primer, ON15284, resides on the retained intron sequence (intron 1 of variant 1 ), which therefore is lacking in the mRNA of the first splice variant; the second primer was ON15281 on exon 1 (Figure 4I and Additional file 1: Table S3). A 111-bp cDNA fragment was predicted for variant 1 and a 158-bp fragment for variant 2; the RT-PCR yielded fragments of the expected sizes (Figure 5I, Additional file 1: Table S3). Quantitative real-time RT-PCR showed that the expression of the first splice variant of oee1 is $\sim 17$ fold higher than actin; whereas the expression of the second variant is $\sim 11$ fold less than actin (Figure 7D).

The bioinformatic analysis of EST sequences revealed a third splice variant of ooe1. For verification of this variant by RT-PCR, one primer, ON15283, only binds to the exonexon junction of exons 1 and 3, which emerges only after removal of a $356 \mathrm{bp}$ fragment between exon 1 and exon 3 by splicing; the second primer was ON15281 on exon 1 (Figure 4I and Additional file 1: Table S3). A 112-bp cDNA fragment was predicted for variant 3 . However, we were not able to confirm this variant by RT-PCR (Figure 5I, middle lane).

\section{Verification of alternative $5^{\prime}$ splice sites}

The sample gene for alternative $5^{\prime}$ splice sites was ppi1, which codes for a protein with an Ypi1 domain (Additional file 1: Table S2). The Ypi1 domain is a Saccharomyces cerevisiae type 1 protein phosphatase inhibitor [122]. The gene ppil of Volvox is a quite small gene with a single intron, which is $100 \mathrm{bp}$ in length. The first splice variant of ppi1 encodes a 100-amino-acid polypeptide, which shows $82 \%$ identity to the FAP255 protein of Chlamydomonas. FAP255 is a flagellar associated protein found in the flagellar proteome [59,123] (Additional file 1: Table S2, Additional file 1: Figure S10A). In the second splice variant, $21 \mathrm{bp}$ at the $5^{\prime}$ side of the intron are retained and thereby a premature stop codon is introduced (Figure 4J). As a consequence, a shortened protein isoform with a truncated Ypi1 domain is produced (Additional file 1: Figure S10B).

For verification of the first splice variant of ppi1 by RTPCR, one primer, ON15302, only binds to the exon-exon junction of exons 1 and 2, which emerges only after complete removal of the 100 bp of intron 1 by splicing; the second primer is ON15300 on exon 1 (Figure 4J and Additional file 1: Table S3). For amplification of the second splice variant, one primer, ON15301, resides on the retained 21 bp of intron 1 , which therefore is lacking in the mRNA of the first splice variant; the second primer was ON15300 on exon 1 (Figure 4J and Additional file 1: Table S3). A 140-bp cDNA fragment was predicted for variant 1 and a 141-bp fragment for variant 2; the RT-PCR yielded fragments of the expected sizes (Figure 5J, Additional file 1: Table S3); the band of variant 2 showed a lower intensity than the band of variant 1. Quantitative real-time RT-PCR showed that the expression of the first splice variant of ppi1 is $\sim 70 \%$ higher than the expression of actin and even $\sim 1000 \%$ higher than the expression of variant 2 .

\section{Discussion}

\section{A comparative view on alternative splicing in Volvox}

This work provides a bioinformatic analysis of 132,038 ESTs in relation to alternative splicing events in the multicellular green alga Volvox. The results show that $66.7 \%$ of the alternative splice events are within the coding region (Figure 3A) and thus have an effect on the protein sequence and, as a consequence, frequently also on protein structure and function. The remaining $33.3 \%$ of all alternative splice events in Volvox were within the $5^{\prime}$ and $3^{\prime}$ UTRs (Figure 3A), which is higher than reported data (21-28.5\%) from Arabidopsis (Figure 3C), mouse and human [5,124-127] and this study). Thus, UTRs in the alga Volvox are more frequently target of alternative splicing than UTRs in the land plant Arabidopsis (Figures 3A and 3C). Alternative splicing of UTRs can play a key role both in regulation and in the production of mRNA diversity $[11,128]$. Moreover, changes in mRNA secondary structure can affect RNA processing, mRNA stability and translation of the messenger [129-131]. In addition, it possibly creates phenotypic variability [132]. In multicellular organisms, regulation of mRNA stability plays a crucial role in development, growth and differentiation [133]. That data indicate that there might be more variability and diversity through alternative splicing in Volvox UTRs than in Arabidopsis UTRs (Table 1, Figures 3A and 3C).

The distribution scheme of the different types of alternative splicing in Volvox shows that intron retention is the predominant type, while exon skipping is only a smaller part (46.5\% versus 9.5\%; Table 1, Figure 2A). Interestingly, the situation in human is just opposite to the situation in Volvox: there are only $1 \%$ intron retention events and $35.6 \%$ exon skipping events (Table 1). These highly differing distributions could result from different genome features. For example, the introns in human are much longer than in Volvox, or to be more exact, the median sizes of introns are 1,504 bp versus 358 bp $[58,135]$. The size of introns is crucial factor in the mechanism of intron retention, i.e., short introns were shown to be much more frequently retained than longer introns [136-138]. On the contrary, an increase in intron length correlates positively with promotion of the exon skipping mechanism [65,139,140]. Therefore, intron length is the determining factor for the switch from the intron definition mechanism, in which the $5^{\prime}$ and 3 ' splice sites are initially recognized and paired across the intron, to the exon definition mechanism, in which splice sites are paired first across the exons, with spliceosome assembly proceeding through subsequent pairing of exon units [141]. Thus, a plethora of short introns is Volvox is probably recognized and spliced out through the intron definition mechanism, while in human the exon definition 
Table 1 The occurrence of alternative splicing events in Volvox in comparison to Chlamydomonas, Arabidopsis and human

\begin{tabular}{|c|c|c|c|c|c|c|}
\hline Organism & $\begin{array}{c}\text { Total number of } \\
\text { included ESTs/cDNAs }\end{array}$ & $\begin{array}{l}\text { Alternative } \\
\text { splicing [\%] }\end{array}$ & $\begin{array}{c}\text { Exon } \\
\text { skipping [\%] }\end{array}$ & $\begin{array}{c}\text { Intron } \\
\text { retention [\%] }\end{array}$ & $\begin{array}{c}\text { Alternative } \\
\text { 5' splice site [\%] }\end{array}$ & $\begin{array}{c}\text { Alternative } \\
\text { 3'splice site [\%] }\end{array}$ \\
\hline Volvox $_{\text {carteri }}{ }^{*}$ & 132,038 & 2.9 & 9.5 & 46.5 & 17.9 & 21.9 \\
\hline Chlamydomonas reinhardtii ${ }^{* *}$ & 252,484 & 3 & 11.9 & 50.0 & 11.6 & 25.8 \\
\hline Arabidopsis thaliana $^{3}$ & 541.594 & 20 & 3 & 41 & 18 & 38 \\
\hline Human $^{4^{* * *}}$ & 435 million cDNA reads & 90 & 40 & 3 & 8 & 18 \\
\hline
\end{tabular}

${ }^{1}$ this study, ${ }^{2}[53],{ }^{3}[26],{ }^{4}[16,134]$.

* $4.2 \%$ show other alternative splicing events.

${ }^{*} 0.7 \%$ show both alternative 5 ' splice site and alternative 3 ' splice sites.

*** $32.7 \%$ show other alternative splicing events such as exclusive exon, alternative first exon, alternative last exon and tandem 3' UTR.

mechanism is dominant because a vast number of exons is flanked by long introns [140,141]. It should be noted that the introns of Chlamydomonas are even somewhat ( 25\%) shorter than those in Volvox, i.e., the average lengths are $491 \mathrm{bp}$ and $373 \mathrm{bp}$, respectively (Additional file 1: Table $\mathrm{S} 1)$, but the calculated intron retention rate is about the same in both organisms (Figure 2, Table 1). However, the intron lengths of both species can be considered as short and therefore the intron definition mechanism seems to apply for both species to the same extend.

Our analysis of ESTs in Volvox revealed that 2.9\% of all Volvox genes undergo alternative splicing, which is similar to the reported 3\% for Chlamydomonas [53]. The absolute numbers of alternative splicing events were 580 for Volvox and 493 for Chlamydomonas (Figure 2). However, it should be noted that the absolute numbers and percentages have been calculated based on different total EST numbers, i.e., the number of analyzed ESTs in Chlamydomonas $(252,484)$ was almost twice that of Volvox $(132,038)$ (Table 1) even if the total number of protein-coding loci is about the same in Volvox $(14,520)$ and Chlamydomonas $(14,516)$ [58]. Because the total number of ESTs is a critical value for detection of alternative splicing events, probably more alternative splicing events remained undetected in Volvox than in Chlamydomonas. These results and considerations indicate that actually the rate of alternatively spliced genes is higher in Volvox than in Chlamydomonas and, thus, also the variability and diversity through alternative splicing appears to be higher in Volvox. However, the data presented here are not corrected for the amount of transcript evidence available.

The number of ESTs analyzed in Volvox $(132,038)$ is similar to the number of ESTs analyzed in Arabidopsis $(176,915)$ in a study by Zhu et al. in 2003 [22], which came to a value of $1.5 \%$ alternatively spliced genes for Arabidopsis (Additional file 1: Figure S12). As mentioned above, nine years later, after sequencing countless more ESTs, the rate was calculated to be $61 \%[18,19]$. Therefore, in actual fact, alternative splicing in the alga Volvox might be just as common as in higher eukaryotes like Arabidopsis, Drosophila or even human [13,17] [14-16,19].

\section{Some striking alternative splicing events in Volvox}

During our genome-wide analysis, we found some genes with remarkable alternative splicing variants regarding the size or number of excluded introns and exons.

One of these genes is efg8, which is subject to exon skipping (Figure 4B). The first splicing variant of efg8 contains 15 exons. In the second splicing variant even six consecutive exons (5 to 10) are skipped at once. These exons are quite short, i.e., between 44 and 121 bp in size, and also the sequences between the exons are short (between 162 and 718 bp). However, two extremely long introns flank the skipped sequence: The introns 4 (between exon 4 and 5) and 10 (between exon 10 and 11) are 3,958 and 4,407 bp in length, respectively (Figure 4B). Thus, in the second splicing variant an intron of $10,772 \mathrm{bp}$ is spliced out, which contains exons 5-10 and introns 4-11. This spliced fragment of the second variant is one of the longest introns identified in Volvox so far (Figure 4B). In Arabidopsis and maize, the longest reported introns are about 3 and $7 \mathrm{~kb}$ in length, respectively [142-144]. The longest introns among all plants have been identified in tobacco and rice, which are about 17 and $28 \mathrm{~kb}$ in length, respectively $[145,146]$. In general, especially long introns can contain regulatory elements to control gene expression under certain conditions (development, cell-type specificity, environmental influences) $[147,148]$.

The selEFf gene is also subject to exon skipping. The first splicing variant of selEFf contains 7 exons. In the second splicing variant a single small exon (exon 4), only 56 bp in length, is skipped. This exon is flanked by two extremely long introns, which are 7,996 and 8,313 bp in length, respectively (Figure 4G). Thus, in the second splicing variant an intron of $16,365 \mathrm{bp}$ is spliced out (Figure 4G), which contains exon 4, intron 3 and intron 4 . This spliced $\sim 16 \mathrm{~kb}$ fragment of the second variant is one of the longest introns identified in the plant lineage so far; it is longer than any intron in Arabidopsis or maize.

\section{Alternative splicing and organismal complexity}

Alternative splicing is a major mechanism for generating proteome diversity, which probably was co-opted in 
evolution of multicellular complexity [149]; it plays a critical role in differentiation and development of multicellular eukaryotes $[128,150]$. Because Volvox only has about the same number of protein-coding genes compared to its unicellular relative Chlamydomonas, alternative splicing could have contributed to an increase in proteome diversity when a unicellular Chlamydomonas-like ancestor evolved to the multicellular Volvox alga with its differentiated cells. In more concrete terms, the transition to multicellularity in volvocine algae required a proteome with an increased capacity to address new traits and tasks like multicellularity, cell differentiation, multicellular motility and phototaxis as well as egg and sperm formation. Alternative splicing seems to be particularly important for the generation of new or modified regulatory proteins, which are indispensable in the evolution of multicellular complexity [125]. Especially transcription factors and signal transducers that act as key regulators in complex, multicellular systems seem to be subject to extensive alternative splicing $[124,125,151]$.

In our analysis we found some evidence that alternative splicing actually affects key regulators. For example, the retinoblastoma gene rbrl/mat3, which codes for a key cell cycle and cell size regulator [49,152], is only subject to alternative splicing in the multicellular alga Volvox; no such event has been reported its close unicellular relative Chlamydomonas $[49,50,152]$. This gene also shows gender-specific splicing in Volvox and it is believed to be involved by the evolution of oogamy $[50,153]$. Also worth mentioning is the general distribution of alternatively spliced genes in Volvox in relation to its unicellular relative Chlamydomonas. For it, we took one-hundred alternatively spliced genes from Volvox and compared them with the corresponding orthologs in Chlamydomonas. Ten of these one-hundred genes were those that were selected for experimental verification and another ninety alternatively spliced genes were randomly selected. The results are shown in Figure 8 and Additional file 1: Table S4. The comparison demonstrates that the largest fraction of alternatively spliced genes in Volvox (70\% of the analyzed genes) does not exhibit alternative splicing in the unicellular alga Chlamydomonas. The lack of alternative splicing events for those genes in Chlamydomonas is not due to poor EST support, because the total number of ESTs is lower for the Volvox genes than for their orthologs in Chlamydomonas (Figure 8 and Additional file 1: Table S4). This observation supports the idea that alternative splicing events increased during evolution from the unicellular ancestor to the multicellular alga Volvox in order to expand the transcript diversity and, as a consequence, the proteomic diversity. Recently, the group of Urrutia also demonstrated a strong association between alternative splicing and organism complexity [1]. In addition to alternative splicing, gene duplication followed

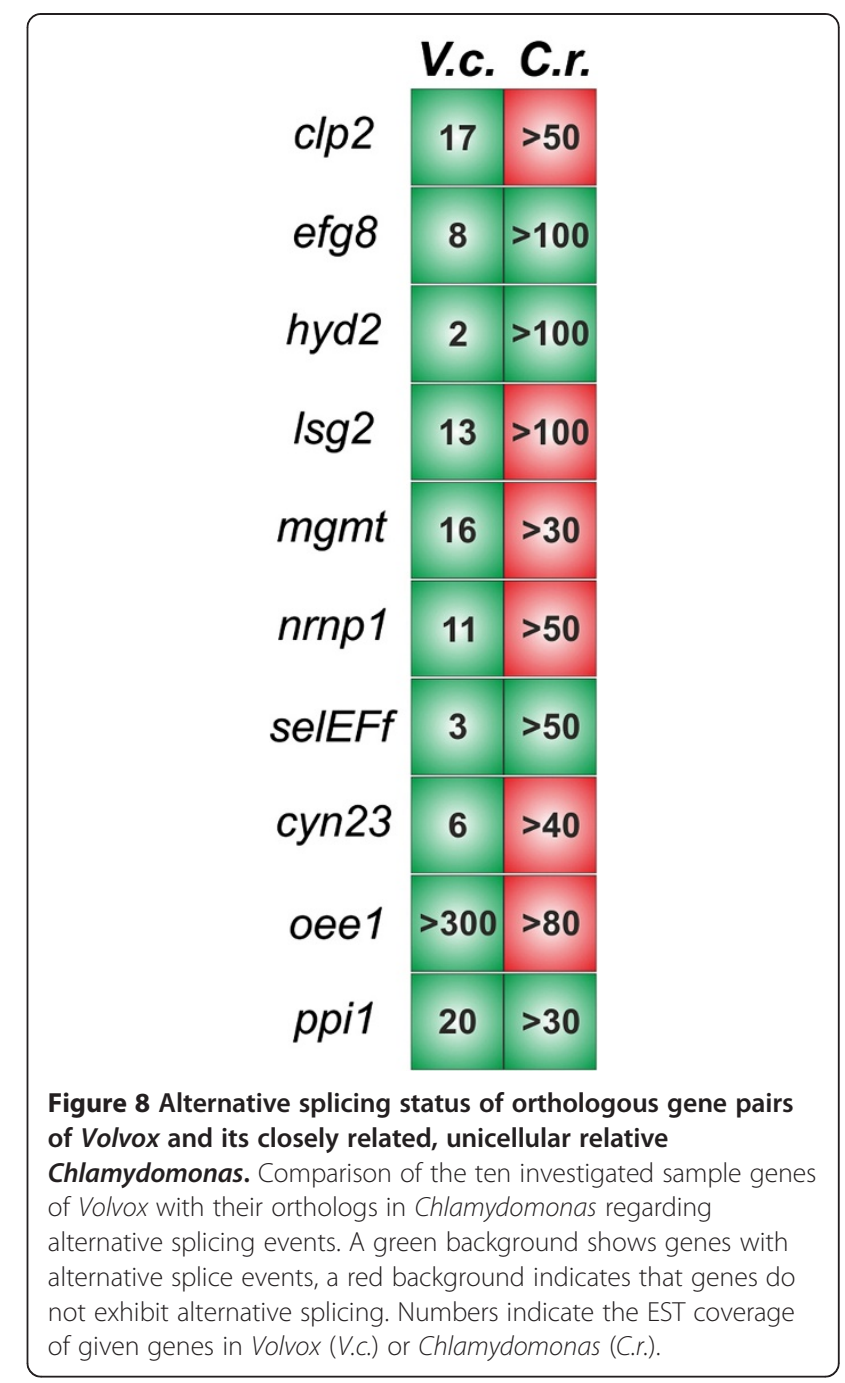

by divergence also increases proteome diversity [65]. During evolution of multicellular volvocine algae, the number of members in several protein families increased significantly through gene duplication. The families with the most extensive expansions are the VMPs, the pherophorins and the cyclin Ds, which are involved in the (partly gender-specific) biosynthesis of the extracellular matrix and in the regulation of cell division program during development [58].

However, in contrast to the extent of gene duplications, which remains invariant after sequencing of the genome, it can be expected that the percentage of alternatively spliced genes will increase strongly in Volvox when more and more EST data and full-length cDNA sequences become available, just as it happened earlier in Arabidopsis $[18,19,22-24,154]$. In all probability, deep sequencing of the Volvox transcriptome during asexual and sexual development, during embryonic cleavage divisions and cellular differentiation and under various environmental conditions (e.g., heat and light stress or nutrient deprivation) 
will yield numerous new splicing variants. Thus, it is becoming increasingly clear that alternative splicing is not an exception, but relatively widespread in Volvox and other eukaryotes. This degree raises quite difficult questions: Do all splice isoforms have functional significance? How big is the noise in the splicing process? At which extent do truncated and misfolded proteins play a role in cellular regulation? Which amount of inadvertently produced isoforms can be tolerated by a cell? However, frequently alternative splicing seems to be part of molecular mechanisms that allow (some) cells of an organism to decrease the concentration of certain (functional) proteins without changing the transcription rate of the corresponding genes. Instead, shortened or modified non-functional mRNA variants are generated by alternative splicing. In this way, specific cellular and physiological processes can be attenuated, altered or even intensified at the posttranscriptional level.

In human, splicing error rates of 1 to 10 percent have been calculated $[155,156]$, but it remains difficult to distinguish between functional and non-functional isoforms because also truncated proteins might have a function. In several studies, criteria like abundance, conservation of splicing events across species, tissue specificity and developmental stage specificity have been used to assess functionality [155,157]. Different models proceed on the assumption that the splicing machinery makes mistakes at a constant error rate, is dependent on the number of introns or is determined by the number of introns and transcript abundance [155,157].

However, the noise in the splicing process should not be considered as a collateral damage of splicing. Noise in splicing might have been an important factor in the evolution of multicellularity in volvocine algae because it creates a landscape of opportunities in which novel biological activity can be explored at very little cost [155].

\section{Conclusions}

Our results show that the approach for prediction of alternative splicing events in Volvox was accurate and reliable. Moreover, quantitative real-time RT-PCR appears to be useful for analyses of relationships between the appearance of specific alternative splicing variants and different kinds of physiological, metabolic and developmental processes as well as responses to environmental changes.

\section{Methods}

\section{Strain and culture conditions}

Synchronous cultures of Volvox carteri f. nagariensis strain EVE (wild-type female) [158] were grown in standard Volvox medium [159] at $28^{\circ} \mathrm{C}$ in an $8 \mathrm{~h}$ dark $/ 16 \mathrm{~h}$ light (10,000 lux) cycle [160].

\section{Data sources}

Genomic sequences of Volvox carteri f. nagariensis (strain Eve) came from the Volvox carteri whole genome shotgun sequencing project [58] (GenBank project accession No. ACJH00000000). The genomic contigs of Volvox are available both on the web pages of phytozome (v10), the plant comparative genomics portal of the Department of Energy's Joint Genome Institute (JGI) (http://www.phytozome.net/), and on the web pages of the Volvox genome portal of JGI (http://genome.jgi-psf. org/Volca1/Volca1.info.html). The sequences of 132,038 ESTs of Volvox carteri $\mathrm{f}$. nagariensis were generated as part of the Volvox genome project [58] and are available at the GenBank EST database (http://www.ncbi.nlm.nih. gov/dbEST/) and at the PlantGDB web resource (http:// www.plantgdb.org/). These ESTs were derived from the female Volvox carteri f. nagariensis strains Eve and Eve10 and the male strain 69-1b [58]. RNAs from Eve and 69-1b were isolated 1.5, 10, 24, 48 hours after sexual-induction and subsequently pooled. For Eve10, extracted RNAs from 2-4 and 32-128 cell stages were pooled. The sequences both of genomic contigs and ESTs of Chlamydomonas came from the Chlamydomonas whole genome shotgun sequencing project [59]. The data are available both on the web pages of phytozome (v10) and at the PlantGDB web resource. The genomic and EST sequences of Arabidopsis came from the Arabidopsis Genome Initiative (AGI) [31]. The data are available both on the web pages of The Arabidopsis Information Resource (TAIR) (http://www.arabidopsis. org/) and at the PlantGDB web resource.

\section{Genomic mapping of expressed sequence clusters}

The ESTs of the three species Volvox, Chlamydomonas and Arabidopsis were aligned to the corresponding genomic contigs and genome sequences using BLAT, a BLAST-like alignment tool [67]. To avoid double counting of paralogs, we only used the best alignment. Sequences with less than 95\% identity were removed from further analysis. The resulting alignments were then clustered by genomic location where each cluster is formed by the set of all ESTs which overlap at a given location. The splice site consensus sequences (GT/AG) were identified and sequences without splice site consensus sequence were also removed. Subsequently, an alternative splicing graph of potential splice variants was constructed. An intron in the splice graph was constructed when there was EST evidence of a transcript with appropriate splice sites.

\section{Alternative splicing analysis}

From the splice graphs, we identified alternatively spliced isoforms. Isoforms with alternative transcription starts or ends were not considered further in this paper. The isoforms were divided into four major groups of alternative 
splicing events: exon skipping, intron retention, alternative $5^{\prime}$ and alternative 3 ' splicing. This was obtained by searching for patterns of exons and introns that are consistent with these events. In addition, there were instances of more complex splice forms, which were not covered by the above four simple alternative splicing events. To obtain high quality events, only events were included where the amount of sequence evidence for both splice alternatives was within ten times of each other. This was to exclude spurious events due to a small number of ESTs.

\section{Primer design}

For verification of alternative splicing events, primers were designed such that they have similar melting temperatures, allowing both primers to anneal roughly at the same temperature in RT-PCR and real-time RT-PCR experiments. For each candidate gene, three pairs of primers were chosen to amplify the first and the second splice variant separately and also both splice variants together in one reaction tube (Figure 4 and Additional file 1: Table S3). The primers were designed using the primer analysis software Oligo 6 (Molecular Biology Insights, Cascade, CO), DNASIS (version 7.00; Hitachi Software Engineering, South San Francisco, CA), or Primer Express (Applied Biosystems, Foster City, CA).

\section{Isolation of total RNA}

Total RNA was extracted from $1 \mathrm{~g}$ frozen algae using $10 \mathrm{ml}$ of the phenol-based TRI Reagent (Sigma-Aldrich, St. Louis, $\mathrm{MO})$ and $3 \mathrm{ml}$ trichloromethane. RNA was precipitated from the aqueous phase by addition of isopropanol. All preparation and handling steps of RNA took place under RNase-free conditions. After final washing steps with ethanol, RNA was dissolved in RNase-free water and stored at $-70^{\circ} \mathrm{C}$ until used. RNA quantity and purity were determined by measuring the $260 / 280$ ratio using an UV/visible spectrophotometer (Ultrospec 2100 pro, GE Healthcare, Uppsala, Sweden). The quality of RNA was verified by electrophoresis of $0.5 \mu \mathrm{g}$ RNA in a $1.3 \%$ agarose-formaldehyde gel.

\section{RT-PCR}

$1 \mu \mathrm{g}$ of extracted total RNA was treated with 5 units of DNase I (Promega, Madison, WI) for $15 \mathrm{~min}$ at room temperature and then DNase I was inactivated at $75^{\circ} \mathrm{C}$ for 10 min. 1 unit of M-MLV Reverse Transcriptase (Promega, Madison, WI) and $1 \mu \mathrm{M}$ of reverse primer were added for synthesis of the first strand $\mathrm{CDNA}$ at $50^{\circ} \mathrm{C}$ for $60 \mathrm{~min}$ (Figure 4, Additional file 1: Table S1). The synthesized cDNA was used as a template for PCR according to standard protocols [161].

\section{Quantitative real-time RT-PCR}

Quantitative real-time RT-PCR was performed on a DNA Engine Opticon Continuous Fluorescence Detection System
(MJ Research) using the SensiMix one-step kit (Quantace) as described previously [78]. $300 \mathrm{ng}$ total RNA was used per $25 \mu \mathrm{l}$ of reaction volume. The thermal cycling conditions were identical for all quantification experiments, i.e. after the first cDNA synthesis at $50^{\circ} \mathrm{C}$ for $30 \mathrm{~min}$, DNA polymerase was activated at $95^{\circ} \mathrm{C}$ for $10 \mathrm{~min}$, followed by 40 cycles of denaturation at $95^{\circ} \mathrm{C}$ for $20 \mathrm{~s}$, annealing at $55^{\circ}$ $\mathrm{C}$ for $30 \mathrm{~s}$ and extension at $72^{\circ} \mathrm{C}$ for $40 \mathrm{~s}$. The expression levels of splice variants were calculated in relation to a reference gene, the housekeeping gene actin [76,78,162], using the $2^{-\Delta \Delta \mathrm{Ct}}$ method $[163,164]$. The $\mathrm{Ct}, \Delta \mathrm{Ct}$, and $\Delta \Delta \mathrm{Ct}$ values were calculated as described previously [78]. All real-time RT-PCR experiments were carried out in triplicate together with controls lacking RT or template. The final products of all real-time RT-PCR reactions were visualized using agarose gel electrophoresis to ensure amplification of a single product of the correct size.

\section{Additional file}

Additional file 1: Supplemental Material. Supplemental Figures S1 to S12 Supplemental Tables S1 to S4 and Supplemental References.

\section{Abbreviations}

EST: Expressed sequence tags; UTR: Untranslated region; mRNA: Messenger mRNA; RT-PCR: Reverse transcription polymerase chain reaction.

\section{Competing interests}

The authors declare that they have no competing interests.

\section{Authors' contributions}

AK conducted the molecular biological experiments and wrote the first version of the manuscript. CSO and GR did the bioinformatic analysis. AH critically evaluated the data and finalized the manuscript. All authors read and approved the final manuscript.

\section{Acknowledgements}

We thank Stefanie Heinze and Kordula Puls for technical assistance and Ghazaleh Nematollahi for her assistance with the data analysis of alternative splicing events. We acknowledge the support of the Deutsche Forschungsgemeinschaft (DFG) and the Open Access Publication Funds of Bielefeld University, which funded the article processing charges. AK was supported by DFG grant KI 1779/1-1.

\section{Author details}

${ }^{1}$ Department of Cellular and Developmental Biology of Plants, University of Bielefeld, Universitätsstr. 25, D-33615 Bielefeld, Germany. ${ }^{2}$ Machine Learning Group, NICTA Canberra Research Laboratory, Canberra, Australia. ${ }^{3}$ Biomedical Data Science Group, Memorial Sloan-Kettering Cancer Center, 1275 York Avenue, New York City, NY 10065, USA

Received: 30 June 2014 Accepted: 11 December 2014 Published: 16 December 2014

\section{References}

1. Chen L, Bush SJ, Tovar-Corona JM, Castillo-Morales A, Urrutia AO: Correcting for differential transcript coverage reveals a strong relationship between alternative splicing and organism complexity. Mol Biol Evol 2014, 31(6):1402-1413.

2. Stamm S, Ben-Ari S, Rafalska I, Tang Y, Zhang Z, Toiber D, Thanaraj TA, Soreq $\mathrm{H}$ : Function of alternative splicing. Gene 2005, 344:1-20.

3. Keren H, Lev-Maor G, Ast G: Alternative splicing and evolution: diversification, exon definition and function. Nat Rev Genet 2010, 11(5):345-355.

4. Reddy AS: Nuclear pre-mRNA splicing in plants. Crit Rev Plant Sci 2001, 20(6):523-571. 
5. Reddy AS: Alternative splicing of pre-messenger RNAs in plants in the genomic era. Annu Rev Plant Biol 2007, 58:267-294.

6. Gassmann W: Alternative splicing in plant defense. Curr Top Microbiol Immunol 2008, 326:219-233.

7. Cáceres JF, Kornblihtt AR: Alternative splicing: multiple control mechanisms and involvement in human disease. Trends Genet 2002, 18(4):186-193.

8. Grabowski PJ: Splicing regulation in neurons: tinkering with cell-specific control. Cell 1998, 92(6):709-712.

9. Grabowski PJ, Black DL: Alternative RNA splicing in the nervous system. Prog Neurobiol 2001, 65(3):289-308.

10. Stamm S, Zhang MQ, Marr TG, Helfman DM: A sequence compilation and comparison of exons that are alternatively spliced in neurons. Nucleic Acids Res 1994, 22(9):1515-1526.

11. Licatalosi DD, Darnell RB: RNA processing and its regulation: global insights into biological networks. Nat Rev Genet 2010, 11(1):75-87.

12. Black DL: Mechanisms of alternative pre-messenger RNA splicing. Annu Rev Biochem 2003, 72:291-336.

13. Johnson JM, Castle J, Garrett-Engele P, Kan Z, Loerch PM, Armour CD, Santos R, Schadt EE, Stoughton R, Shoemaker DD: Genome-wide survey of human alternative pre-mRNA splicing with exon junction microarrays. Science 2003, 302(5653):2141-2144.

14. Kampa D, Cheng J, Kapranov P, Yamanaka M, Brubaker S, Cawley S, Drenkow J, Piccolboni A, Bekiranov S, Helt G, Tammana H, Gingeras TR: Novel RNAs identified from an in-depth analysis of the transcriptome of human chromosomes 21 and 22. Genome Res 2004, 14(3):331-342.

15. Pan $Q$, Shai $O$, Lee $L$, Frey BJ, Blencowe BJ: Deep surveying of alternative splicing complexity in the human transcriptome by high-throughput sequencing. Nat Genet 2008, 40(12):1413-1415.

16. Wang ET, Sandberg R, Luo S, Khrebtukova I, Zhang L, Mayr C, Kingsmore SF, Schroth GP, Burge CB: Alternative isoform regulation in human tissue transcriptomes. Nature 2008, 456(7221):470-476.

17. Graveley BR, Brooks AN, Carlson JW, Duff MO, Landolin JM, Yang L, Artieri CG, van Baren MJ, Boley N, Booth BW, Brown JB, Cherbas L, Davis CA, Dobin A, Li R, Lin W, Malone JH, Mattiuzzo NR, Miller D, Sturgill D, Tuch BB, Zaleski C, Zhang D, Blanchette M, Dudoit S, Eads B, Green RE, Hammonds A, Jiang L, Kapranov P, et al: The developmental transcriptome of Drosophila melanogaster. Nature 2011, 471(7339):473-479.

18. Filichkin SA, Priest HD, Givan SA, Shen R, Bryant DW, Fox SE, Wong WK, Mockler TC: Genome-wide mapping of alternative splicing in Arabidopsis thaliana. Genome Res 2010, 20(1):45-58.

19. Marquez Y, Brown JW, Simpson C, Barta A, Kalyna M: Transcriptome survey reveals increased complexity of the alternative splicing landscape in Arabidopsis. Genome Res 2012, 22(6):1184-1195.

20. Barash Y, Calarco JA, Gao W, Pan Q, Wang X, Shai O, Blencowe BJ, Frey BJ: Deciphering the splicing code. Nature 2010, 465(7294):53-59.

21. Ramani AK, Calarco JA, Pan Q, Mavandadi S, Wang Y, Nelson AC, Lee L, Morris $Q$, Blencowe $B J$, Zhen M, Fraser AG: Genome-wide analysis of alternative splicing in Caenorhabditis elegans. Genome Res 2011, 21(2):342-348.

22. Zhu W, Schlueter SD, Brendel V: Refined annotation of the Arabidopsis genome by complete expressed sequence tag mapping. Plant Physiol 2003, 132(2):469-484.

23. lida K, Seki M, Sakurai T, Satou M, Akiyama K, Toyoda T, Konagaya A, Shinozaki K: Genome-wide analysis of alternative pre-mRNA splicing in Arabidopsis thaliana based on full-length cDNA sequences. Nucleic Acids Res 2004, 32(17):5096-5103.

24. Campbell MA, Haas BJ, Hamilton JP, Mount SM, Buell CR: Comprehensive analysis of alternative splicing in rice and comparative analyses with Arabidopsis. BMC Genomics 2006, 7:327.

25. Hori $\mathrm{K}$, Watanabe $\mathrm{Y}$ : Context analysis of termination codons in mRNA that are recognized by plant NMD. Plant Cell Physiol 2007, 48(7):1072-1078.

26. Barbazuk WB, Fu Y, McGinnis KM: Genome-wide analyses of alternative splicing in plants: opportunities and challenges. Genome Res 2008, 18(9):1381-1392.

27. Goodall GJ, Filipowicz W: Different effects of intron nucleotide composition and secondary structure on pre-mRNA splicing in monocot and dicot plants. EMBO J 1991, 10(9):2635-2644.

28. McCullough AJ, Schuler MA: AU-rich intronic elements affect pre-mRNA 5' splice site selection in Drosophila melanogaster. Mol Cell Biol 1993, 13(12):7689-7697.

29. Lim LP, Burge CB: A computational analysis of sequence features involved in recognition of short introns. Proc Natl Acad Sci U S A 2001, 98(20):11193-11198.
30. Goodall GJ, Filipowicz W: The AU-rich sequences present in the introns of plant nuclear pre-mRNAs are required for splicing. Cell 1989, 58(3):473-483

31. Arabidopsis Genome Initiative: Analysis of the genome sequence of the lowering plant Arabidopsis thaliana. Nature 2000, 408(6814):796-815.

32. Lander ES, Linton LM, Birren B, Nusbaum C, Zody MC, Baldwin J, Devon K, Dewar K, Doyle M, FitzHugh W, Funke R, Gage D, Harris K, Heaford A, Howland J, Kann L, Lehoczky J, LeVine R, McEwan P, McKernan K, Meldrim J, Mesirov JP, Miranda C, Morris W, Naylor J, Raymond C, Rosetti M, Santos R, Sheridan A, Sougnez C, et al: Initial sequencing and analysis of the human genome. Nature 2001, 409(6822):860-921.

33. Alexandrov NN, Troukhan ME, Brover W, Tatarinova T, Flavell RB, Feldmann KA: Features of Arabidopsis genes and genome discovered using full-length cDNAs. Plant Mol Biol 2006, 60(1):69-85.

34. Wang BB, Brendel V: Genomewide comparative analysis of alternative splicing in plants. Proc Natl Acad Sci U S A 2006, 103(18):7175-7180.

35. White O, Soderlund C, Shanmugan P, Fields C: Information contents and dinucleotide compositions of plant intron sequences vary with evolutionary origin. Plant Mol Biol 1992, 19(6):1057-1064.

36. Yu J, Hu S, Wang J, Wong GK, Li S, Liu B, Deng Y, Dai L, Zhou Y, Zhang X, Cao M, Liu J,Sun J, Tang J, Chen Y, Huang X, Lin W, Ye C, Tong W, Cong L, Geng J, Han Y, Li L, Li W, Hu G, Li J, Liu Z, Qi Q, Li T, Wang X, et al: A draft sequence of the rice genome (Oryza sativa L. ssp. indica). Science 2002, 296(5565):79-92.

37. Baek JM, Han P, landolino A, Cook DR: Characterization and comparison of intron structure and alternative splicing between Medicago truncatula, Populus trichocarpa, Arabidopsis and rice. Plant Mol Biol 2008, 67(5):499-510.

38. Luehrsen KR, Taha S, Walbot V: Nuclear pre-mRNA processing in higher plants. Prog Nucleic Acid Res Mol Biol 1994, 47:149-193.

39. Jordan $T$, Schornack $S$, Lahaye T: Alternative splicing of transcripts encoding Toll-like plant resistance proteins - what's the functional relevance to innate immunity? Trends Plant Sci 2002, 7(9):392-398.

40. Tanabe N, Yoshimura K, Kimura A, Yabuta Y, Shigeoka S: Differential expression of alternatively spliced mRNAs of Arabidopsis SR protein homologs, atSR30 and atSR45a, in response to environmental stress. Plant Cell Physiol 2007, 48(7):1036-1049.

41. Egawa C, Kobayashi F, Ishibashi M, Nakamura T, Nakamura C, Takumi S: Differential regulation of transcript accumulation and alternative splicing of a DREB2 homolog under abiotic stress conditions in common wheat. Genes Genet Syst 2006, 81(2):77-91.

42. Christensen AH, Sharrock RA, Quail PH: Maize polyubiquitin genes: structure, thermal perturbation of expression and transcript splicing, and promoter activity following transfer to protoplasts by electroporation. Plant Mol Biol 1992, 18(4):675-689.

43. Hopf N, Plesofsky-Vig N, Brambl R: The heat shock response of pollen and other tissues of maize. Plant Mol Biol 1992, 19(4):623-630.

44. Mazzucotelli E, Mastrangelo AA, Crosatti C, Guerra D, Stanca AM, Cattivelli L: Abiotic stress response in plants: when post-transcriptional and posttranslational regulations control transcription. Plant Sci 2008, 174:420-431.

45. Ali GS, Reddy AS: Regulation of alternative splicing of pre-mRNAs by stresses. Curr Top Microbiol Immunol 2008, 326:257-275.

46. Syed NH, Kalyna M, Marquez Y, Barta A, Brown JW: Alternative splicing in plants - coming of age. Trends Plant Sci 2012, 17(10):616-623.

47. James AB, Syed NH, Bordage S, Marshall J, Nimmo GA, Jenkins GI, Herzyk P, Brown JW, Nimmo HG: Alternative splicing mediates responses of the Arabidopsis circadian clock to temperature changes. Plant Cell 2012, 24(3):961-981.

48. Huber O, Sumper M: Algal-CAMs: isoforms of a cell adhesion molecule in embryos of the alga Volvox with homology to Drosophila fasciclin I. EMBO J 1994, 13(18):4212-4222

49. Kianianmomeni A, Nematollahi G, Hallmann A: A gender-specific retinoblastoma-related protein in Volvox carteri implies a role for the retinoblastoma protein family in sexual development. Plant Cell 2008, 20(9):2399-2419.

50. Ferris P, Olson BJ, De Hoff PL, Douglass S, Casero D, Prochnik S, Geng S, Rai R, Grimwood J, Schmutz J, Nishii I, Hamaji T, Nozaki H, Pellegrini M, Umen JG: Evolution of an expanded sex-determining locus in Volvox. Science 2010, 328(5976):351-354.

51. Fuhrmann M, Stahlberg A, Govorunova E, Rank S, Hegemann P: The abundant retinal protein of the Chlamydomonas eye is not the photoreceptor for phototaxis and photophobic responses. J Cell Sci 2001, 114(Pt 21):3857-3863. 
52. Schroda M, Vallon O, Whitelegge JP, Beck CF, Wollman FA: The chloroplastic GrpE homolog of Chlamydomonas: two isoforms generated by differential splicing. Plant Cell 2001, 13(12):2823-2839.

53. Labadorf A, Link A, Rogers MF, Thomas J, Reddy AS, Ben-Hur A: Genome-wide analysis of alternative splicing in Chlamydomonas reinhardtii. BMC Genomics 2010, 11:114.

54. Herron MD, Hackett JD, Aylward FO, Michod RE: Triassic origin and early radiation of multicellular volvocine algae. Proc Natl Acad Sci U S A 2009, 106(9):3254-3258.

55. Sanderson MJ: Molecular data from 27 proteins do not support a Precambrian origin of land plants. Am J Bot 2003, 90(6):954-956.

56. Peterson KJ, Butterfield NJ: Origin of the Eumetazoa: testing ecological predictions of molecular clocks against the Proterozoic fossil record. Proc Natl Acad Sci U S A 2005, 102(27):9547-9552.

57. Kirk DL: A twelve-step program for evolving multicellularity and a division of labor. Bioessays 2005, 27(3):299-310.

58. Prochnik SE, Umen J, Nedelcu AM, Hallmann A, Miller SM, Nishii I, Ferris P, Kuo A, Mitros T, Fritz-Laylin LK, Hellsten U, Chapman J, Simakov O, Rensing SA, Terry A, Pangilinan J, Kapitonov V, Jurka J, Salamov A, Shapiro H, Schmutz J, Grimwood J, Lindquist E, Lucas S, Grigoriev IV, Schmitt R, Kirk D, Rokhsar DS: Genomic analysis of organismal complexity in the multicellular green alga Volvox carteri. Science 2010, 329(5988):223-226.

59. Merchant SS, Prochnik SE, Vallon O, Harris EH, Karpowicz SJ, Witman GB, Terry A, Salamov A, Fritz-Laylin LK, Marechal-Drouard L,Marshall WF, Qu LH, Nelson DR, Sanderfoot AA, Spalding MH, Kapitonov W, Ren Q, Ferris P, Lindquist E, Shapiro H, Lucas SM, Grimwood J, Schmutz J, Cardol P, Cerutti H, Chanfreau G, Chen CL, Cognat V, Croft MT, Dent R, et al: The Chlamydomonas genome reveals the evolution of key animal and plant functions. Science 2007, 318(5848):245-250

60. Pennisi E: Volvox genome shows it doesn't take much to be multicellular. Science 2010, 329(5988):128-129.

61. Irimia M, Penny D, Roy SW: Coevolution of genomic intron number and splice sites. Trends Genet 2007, 23(7):321-325.

62. Holland LZ, Short $S$ : Alternative splicing in development and function of chordate endocrine systems: a focus on Pax genes. Integr Comp Biol 2010, 50(1):22-34.

63. Grabowski P: Alternative splicing takes shape during neuronal development. Curr Opin Genet Dev 2011, 21(4):388-394.

64. Lozada-Chávez I, Stadler PF, Prohaska SJ: "Hypothesis for the modern RNA world": a pervasive non-coding RNA-based genetic regulation is a prerequisite for the emergence of multicellular complexity. Orig Life Evol Biosph 2011, 41(6):587-607.

65. Kim E, Magen A, Ast G: Different levels of alternative splicing among eukaryotes. Nucleic Acids Res 2007, 35(1):125-131.

66. Roy $M$, Kim N, Xing $Y$, Lee $C$ : The effect of intron length on exon creation ratios during the evolution of mammalian genomes. RNA 2008, 14(11):2261-2273.

67. Kent WJ: BLAT - the BLAST-like alignment tool. Genome Res 2002, 12(4):656-664

68. Sparks ME, Brendel V: Incorporation of splice site probability models for non-canonical introns improves gene structure prediction in plants. Bioinformatics 2005, 21 Suppl 3:iii20-iii30.

69. Yu AY, Houry WA: ClpP: a distinctive family of cylindrical energy-dependent serine proteases. FEBS Lett 2007, 581(19):3749-3757.

70. Majeran W, Friso G, van Wijk KJ, Vallon O: The chloroplast ClpP complex in Chlamydomonas reinhardtii contains an unusual high molecular mass subunit with a large apical domain. FEBS J 2005, 272(21):5558-5571.

71. Ekici OD, Paetzel M, Dalbey RE: Unconventional serine proteases: variations on the catalytic Ser/His/Asp triad configuration. Protein Sci 2008, 17(12):2023-2037.

72. Wang J, Hartling JA, Flanagan JM: The structure of ClpP at $2.3 \AA$ resolution suggests a model for ATP-dependent proteolysis. Cell 1997, 91(4):447-456.

73. Bove J, Kim CY, Gibson CA, Assmann SM: Characterization of woundresponsive RNA-binding proteins and their splice variants in Arabidopsis. Plant Mol Biol 2008, 67(1-2):71-88.

74. Moll AG, Lindenmeyer MT, Kretzler M, Nelson PJ, Zimmer R, Cohen CD: Transcript-specific expression profiles derived from sequence-based analysis of standard microarrays. PLoS One 2009, 4(3):e4702.

75. Chamberlain KL, Miller SH, Keller LR: Gene expression profiling of flagellar disassembly in Chlamydomonas reinhardtii. Genetics 2008, 179(1):7-19.

76. Amon $P$, Haas $E$, Sumper M: The sex-inducing pheromone and wounding trigger the same set of genes in the multicellular green alga Volvox. Plant Cell 1998, 10(5):781-789.
77. Hallmann A: The pherophorins: common, versatile building blocks in the evolution of extracellular matrix architecture in Volvocales. Plant J 2006, 45(2):292-307.

78. Nematollahi G, Kianianmomeni A, Hallmann A: Quantitative analysis of cell-type specific gene expression in the green alga Volvox carteri. BMC Genomics 2006, 7(1):321.

79. Fraga D, Meulia T, Fenster S: Real-Time PCR. In Current Protocols Essential Laboratory Techniques. Edited by Gallagher SR, Wiley EA. New York: John Wiley \& Sons; 2008.

80. Hilgenfeld R: Regulatory GTPases. Curr Opin Struct Biol 1995, 5(6):810-817.

81. Agirrezabala $X$, Frank J: Elongation in translation as a dynamic interaction among the ribosome, tRNA, and elongation factors EF-G and EF-Tu. Q Rev Biophys 2009, 42(3):159-200.

82. Kjeldgaard M, Nyborg J: Refined structure of elongation factor EF-Tu from Escherichia coli. J Mol Biol 1992, 223(3):721-742.

83. Kawashima T, Berthet-Colominas C, Wulff M, Cusack S, Leberman R: The structure of the Escherichia coli EF-Tu.EF-Ts complex at 2.5 Å resolution. Nature 1996, 379(6565):511-518.

84. Bourne HR, Sanders DA, McCormick F: The GTPase superfamily: conserved structure and molecular mechanism. Nature 1991, 349(6305):117-127.

85. Berchtold H, Reshetnikova L, Reiser CO, Schirmer NK, Sprinzl M, Hilgenfeld R: Crystal structure of active elongation factor Tu reveals major domain rearrangements. Nature 1993, 365(6442):126-132.

86. Nissen P, Kjeldgaard M, Thirup S, Polekhina G, Reshetnikova L, Clark BF, Nyborg J: Crystal structure of the ternary complex of Phe-tRNAPhe, EF-Tu, and a GTP analog. Science 1995, 270(5241):1464-1472.

87. Adams MW: The structure and mechanism of iron-hydrogenases. Biochim Biophys Acta 1990, 1020(2):115-145

88. Przybyla AE, Robbins J, Menon N, Peck HD Jr: Structure-function relationships among the nickel-containing hydrogenases. FEMS Microbiol Rev 1992, 8(2):109-135.

89. Happe T, Kaminski A: Differential regulation of the Fe-hydrogenase during anaerobic adaptation in the green alga Chlamydomonas reinhardtii. Eur J Biochem 2002, 269(3):1022-1032

90. Forestier M, King P, Zhang L, Posewitz M, Schwarzer S, Happe T, Ghirardi ML, Seibert M: Expression of two [Fe]-hydrogenases in Chlamydomonas reinhardtii under anaerobic conditions. Eur J Biochem 2003, 270(13):2750-2758.

91. Peters JW, Lanzilotta WN, Lemon BJ, Seefeldt LC: X-ray crystal structure of the Fe-only hydrogenase $(\mathrm{Cpl})$ from Clostridium pasteurianum to 1.8 Angstrom resolution. Science 1998, 282(5395):1853-1858.

92. Shimizu T, Inoue T, Shiraishi H: Cloning and characterization of novel extensin-like cDNAs that are expressed during late somatic cell phase in the green alga Volvox carteri. Gene 2002, 284(1-2):179-187.

93. Kinoshita T, Fukuzawa H, Shimada T, Saito T, Matsuda Y: Primary structure and expression of a gamete lytic enzyme in Chlamydomonas reinhardtii: similarity of functional domains to matrix metalloproteases. Proc Natl Acad Sci U S A 1992, 89(10):4693-4697.

94. Hallmann A, Amon P, Godl K, Heitzer M, Sumper M: Transcriptional activation by the sexual pheromone and wounding: a new gene family from Volvox encoding modular proteins with (hydroxy)proline-rich and metalloproteinase homology domains. Plant J 2001, 26(6):583-593.

95. Heitzer M, Hallmann A: An extracellular matrix-localized metalloproteinase with an exceptional QEXXH metal binding site prefers copper for catalytic activity. J Biol Chem 2002, 277(31):28280-28286.

96. Hooper NM: Families of zinc metalloproteases. FEBS Lett 1994, 354(1):1-6.

97. Soejima H, Zhao W, Mukai T: Epigenetic silencing of the MGMT gene in cancer. Biochem Cell Biol 2005, 83(4):429-437.

98. Kaina B, Christmann M, Naumann S, Roos WP: MGMT: key node in the battle against genotoxicity, carcinogenicity and apoptosis induced by alkylating agents. DNA Repair (Amst) 2007, 6(8):1079-1099.

99. Margison GP, Povey AC, Kaina B, Santibáñez Koref MF: Variability and regulation of $\mathrm{O}^{6}$-alkylguanine-DNA alkyltransferase. Carcinogenesis 2003, 24(4):625-635.

100. Daniels DS, Mol CD, Arvai AS, Kanugula S, Pegg AE, Tainer JA: Active and alkylated human AGT structures: a novel zinc site, inhibitor and extrahelical base binding. EMBO J 2000, 19(7):1719-1730.

101. Daniels DS, Woo TT, Luu KX, Noll DM, Clarke ND, Pegg AE, Tainer JA: DNA binding and nucleotide flipping by the human DNA repair protein AGT. Nat Struct Mol Biol 2004, 11(8):714-720.

102. Duguid EM, Rice PA, He C: The structure of the human AGT protein bound to DNA and its implications for damage detection. J Mol Biol 2005, 350(4):657-666. 
103. Dreyfuss G, Kim VN, Kataoka N: Messenger-RNA-binding proteins and the messages they carry. Nat Rev Mol Cell Biol 2002, 3(3):195-205.

104. Maris C, Dominguez C, Allain FH: The RNA recognition motif, a plastic RNA-binding platform to regulate post-transcriptional gene expression. FEBS J 2005, 272(9):2118-2131.

105. Cléry A, Blatter M, Allain FH: RNA recognition motifs: boring? not quite. Curr Opin Struct Biol 2008, 18(3):290-298.

106. Oubridge $C$, Ito N, Evans PR, Teo $\mathrm{CH}$, Nagai K: Crystal structure at $1.92 \AA$ resolution of the RNA-binding domain of the U1A spliceosomal protein complexed with an RNA hairpin. Nature 1994, 372(6505):432-438.

107. Low SC, Berry MJ: Knowing when not to stop: selenocysteine incorporation in eukaryotes. Trends Biochem Sci 1996, 21(6):203-208.

108. Wang P, Heitman J: The cyclophilins. Genome Biol 2005, 6(7):226.

109. Maleszka R, Lupas A, Hanes SD, Miklos GL: The dodo gene family encodes a novel protein involved in signal transduction and protein folding. Gene 1997, 203(2):89-93.

110. Horowitz DS, Lee EJ, Mabon SA, Misteli T: A cyclophilin functions in pre-mRNA splicing. EMBO J 2002, 21(3):470-480.

111. Ingelfinger $D$, Gothel SF, Marahiel MA, Reidt U, Ficner R, Luhrmann R, Achsel $\mathrm{T}$ : Two protein-protein interaction sites on the spliceosome-associated human cyclophilin CypH. Nucleic Acids Res 2003, 31(16):4791-4796.

112. He Z, Li L, Luan S: Immunophilins and parvulins. superfamily of peptidyl prolyl isomerases in Arabidopsis. Plant Physiol 2004, 134(4):1248-1267.

113. Romano P, Gray J, Horton P, Luan S: Plant immunophilins: functional versatility beyond protein maturation. New Phytol 2005, 166(3):753-769.

114. Kallen J, Spitzfaden C, Zurini MG, Wider G, Widmer H, Wuthrich K, Walkinshaw MD: Structure of human cyclophilin and its binding site for cyclosporin A determined by X-ray crystallography and NMR spectroscopy. Nature 1991, 353(6341):276-279.

115. Pflügl G, Kallen J, Schirmer T, Jansonius JN, Zurini MG, Walkinshaw MD: X-ray structure of a decameric cyclophilin-cyclosporin crystal complex. Nature 1993, 361(6407):91-94

116. Zydowsky LD, Etzkorn FA, Chang HY, Ferguson SB, Stolz LA, Ho SI, Walsh CT: Active site mutants of human cyclophilin A separate peptidyl-prolyl isomerase activity from cyclosporin A binding and calcineurin inhibition. Protein Sci 1992, 1(9):1092-1099.

117. Cardenas ME, Lim E, Heitman J: Mutations that perturb cyclophilin A ligand binding pocket confer cyclosporin A resistance in Saccharomyces cerevisiae. J Biol Chem 1995, 270(36):20997-21002.

118. Tam LW, Kirk DL: Identification of cell-type-specific genes of Volvox carteri and characterization of their expression during the asexual life cycle. Dev Biol 1991, 145(1):51-66.

119. Meissner M, Stark K, Cresnar B, Kirk DL, Schmitt R: Volvox germline-specific genes that are putative targets of RegA repression encode chloroplast proteins. Curr Genet 1999, 36(6):363-370.

120. Mayfield SP, Bennoun P, Rochaix JD: Expression of the nuclear encoded OEE1 protein is required for oxygen evolution and stability of photosystem II particles in Chlamydomonas reinhardtii. EMBO J 1987, 6(2):313-318

121. Yi X, McChargue M, Laborde S, Frankel LK, Bricker TM: The manganesestabilizing protein is required for photosystem II assembly/stability and photoautotrophy in higher plants. J Biol Chem 2005, 280(16):16170-16174.

122. García-Gimeno MA, Muñoz I, Ariño J, Sanz P: Molecular characterization of Ypi1, a novel Saccharomyces cerevisiae type 1 protein phosphatase inhibitor. J Biol Chem 2003, 278(48):47744-47752.

123. Pazour GJ, Agrin N, Leszyk J, Witman GB: Proteomic analysis of a eukaryotic cilium. J Cell Biol 2005, 170(1):103-113.

124. Modrek B, Resch A, Grasso C, Lee C: Genome-wide detection of alternative splicing in expressed sequences of human genes. Nucleic Acids Res 2001, 29(13):2850-2859.

125. Zavolan M, Kondo S, Schonbach C, Adachi J, Hume DA, Hayashizaki Y, Gaasterland T: Impact of alternative initiation, splicing, and termination on the diversity of the mRNA transcripts encoded by the mouse transcriptome. Genome Res 2003, 13(6B):1290-1300

126. Gupta S, Zink D, Korn B, Vingron M, Haas SA: Genome wide identification and classification of alternative splicing based on EST data. Bioinformatics 2004, 20(16):2579-2585.

127. Okazaki Y, Furuno M, Kasukawa T, Adachi J, Bono H, Kondo S, Nikaido I, Osato N, Saito R, Suzuki H, Yamanaka I, Kiyosawa H, Yagi K, Tomaru Y, Hasegawa Y, Nogami A, Schönbach C, Gojobori T, Baldarelli R, Hill DP, Bult C, Hume DA, Quackenbush J, Schriml LM, Kanapin A, Matsuda H, Batalov S, Beisel KW, Blake JA, Bradt D, et al: Analysis of the mouse transcriptome based on functional annotation of 60,770 full-length cDNAs. Nature 2002, 420(6915):563-573.

128. Nilsen TW, Graveley BR: Expansion of the eukaryotic proteome by alternative splicing. Nature 2010, 463(7280):457-463.

129. Klaff $P$, Riesner $D$, Steger G: RNA structure and the regulation of gene expression. Plant Mol Biol 1996, 32(1-2):89-106.

130. Nackley AG, Shabalina SA, Tchivileva IE, Satterfield K, Korchynskyi O, Makarov SS, Maixner W, Diatchenko L: Human catechol-O-methyltransferase haplotypes modulate protein expression by altering mRNA secondary structure. Science 2006, 314(5807):1930-1933.

131. Kudla G, Murray AW, Tollervey D, Plotkin JB: Coding-sequence determinants of gene expression in Escherichia coli. Science 2009, 324(5924):255-258.

132. Gommans WM, Mullen SP, Maas S: RNA editing: a driving force for adaptive evolution? Bioessays 2009, 31(10):1137-1145.

133. Surdej P, Riedl A, Jacobs-Lorena M: Regulation of mRNA stability in development. Annu Rev Genet 1994, 28:263-282.

134. Gamazon ER, Stranger BE: Genomics of alternative splicing: evolution, development and pathophysiology. Hum Genet 2014, 133(6):679-687.

135. Fedorova $L$, Fedorov A: Puzzles of the human genome: why do we need our introns? Curr Genomics 2005, 6(8):589-595

136. Galante PA, Sakabe NJ, Kirschbaum-Slager N, de Souza SJ: Detection and evaluation of intron retention events in the human transcriptome. RNA 2004, 10(5):757-765.

137. Stamm S, Zhu J, Nakai K, Stoilov P, Stoss O, Zhang MQ: An alternative-exon database and its statistical analysis. DNA Cell Biol 2000, 19(12):739-756.

138. Zheng CL, Fu XD, Gribskov M: Characteristics and regulatory elements defining constitutive splicing and different modes of alternative splicing in human and mouse. RNA 2005, 11(12):1777-1787.

139. McGuire AM, Pearson MD, Neafsey DE, Galagan JE: Cross-kingdom patterns of alternative splicing and splice recognition. Genome Biol 2008, 9(3):R50.

140. Kandul NP, Noor MA: Large introns in relation to alternative splicing and gene evolution: a case study of Drosophila bruno-3. BMC Genet 2009, 10:67.

141. Fox-Walsh KL, Dou Y, Lam BJ, Hung SP, Baldi PF, Hertel KJ: The architecture of pre-mRNAs affects mechanisms of splice-site pairing. Proc Natl Acad Sci U S A 2005, 102(45):16176-16181.

142. Yanofsky MF, Ma H, Bowman JL, Drews GN, Feldmann KA, Meyerowitz EM: The protein encoded by the Arabidopsis homeotic gene agamous resembles transcription factors. Nature 1990, 346(6279):35-39.

143. Hong RL, Hamaguchi L, Busch MA, Weigel D: Regulatory elements of the floral homeotic gene AGAMOUS identified by phylogenetic footprinting and shadowing. Plant Cell 2003, 15(6):1296-1309.

144. Bruggmann R, Bharti AK, Gundlach H, Lai J, Young S, Pontaroli AC, Wei F, Haberer G, Fuks G, Du C, Raymond C, Estep MC, Liu R, Bennetzen JL, Chan AP, Rabinowicz PD, Quackenbush J, Barbazuk WB, Wing RA, Birren B, Nusbaum C, Rounsley S, Mayer KF, Messing J: Uneven chromosome contraction and expansion in the maize genome. Genome Res 2006 16(10):1241-1251.

145. Kobayashi Y, Dokiya Y, Sugiura M, Niwa Y, Sugita M: Genomic organization and organ-specific expression of a nuclear gene encoding phage-type RNA polymerase in Nicotiana sylvestris. Gene 2001, 279(1):33-40.

146. Tadege M, Sheldon CC, Helliwell CA, Upadhyaya NM, Dennis ES, Peacock WJ: Reciprocal control of flowering time by OsSOC1 in transgenic Arabidopsis and by FLC in transgenic rice. Plant Biotechnol J 2003, 1(5):361-369.

147. Haddrill PR, Charlesworth B, Halligan DL, Andolfatto P: Patterns of intron sequence evolution in Drosophila are dependent upon length and GC content. Genome Biol 2005, 6(8):R67

148. Marais G, Nouvellet $P$, Keightley PD, Charlesworth B: Intron size and exon evolution in Drosophila. Genetics 2005, 170(1):481-485

149. Irimia M, Rukov JL, Penny D, Roy SW: Functional and evolutionary analysis of alternatively spliced genes is consistent with an early eukaryotic origin of alternative splicing. BMC Evol Biol 2007, 7:188.

150. Luco RF, Allo M, Schor IE, Kornblihtt AR, Misteli T: Epigenetics in alternative pre-mRNA splicing. Cell 2011, 144(1):16-26.

151. Taneri B, Snyder B, Novoradovsky A, Gaasterland T: Alternative splicing of mouse transcription factors affects their DNA-binding domain architecture and is tissue specific. Genome Biol 2004, 5(10):R75.

152. Umen JG, Goodenough UW: Control of cell division by a retinoblastoma protein homolog in Chlamydomonas. Genes Dev 2001, 15(13):1652-1661.

153. Umen JG: Evolution of sex and mating loci: an expanded view from volvocine algae. Curr Opin Microbiol 2011, 14(6):634-641. 
154. Xiao YL, Smith SR, Ishmael N, Redman JC, Kumar N, Monaghan EL, Ayele M, Haas BJ, Wu HC, Town CD: Analysis of the CDNAs of hypothetical genes on Arabidopsis chromosome 2 reveals numerous transcript variants. Plant Physiol 2005, 139(3):1323-1337.

155. Melamud E, Moult J: Stochastic noise in splicing machinery. Nucleic Acids Res 2009, 37(14):4873-4886.

156. Pickrell JK, Pai AA, Gilad Y, Pritchard JK: Noisy splicing drives mRNA isoform diversity in human cells. PLoS Genet 2010, 6(12):e1001236.

157. Resch A, Xing Y, Alekseyenko A, Modrek B, Lee C: Evidence for a subpopulation of conserved alternative splicing events under selection pressure for protein reading frame preservation. Nucleic Acids Res 2004, 32(4):1261-1269.

158. Adams CR, Stamer KA, Miller JK, McNally JG, Kirk MM, Kirk DL: Patterns of organellar and nuclear inheritance among progeny of two geographically isolated strains of Volvox carteri. Curr Genet 1990, 18(2):141-153.

159. Provasoli L, Pintner IJ: Artificial media for fresh-water algae: problems and suggestions. In The Ecology of Algae, a Symposium Held at the Pymatuning Laboratory of Field Biology on June 18 and 19, 1959. 1st edition. Edited by Tryon CA, Hartman RT. Pittsburgh, PA: The Pymatuning Symposia in Ecology, Special Publication No. 2., University of Pittsburgh; 1959:84-96.

160. Starr RC, Jaenicke L: Purification and characterization of the hormone initiating sexual morphogenesis in Volvox carteri f. nagariensis lyengar. Proc Natl Acad Sci U S A 1974, 71(4):1050-1054.

161. Sambrook J, Russell DW: Molecular Cloning: A Laboratory Manual (3rd Edition), Vol. 1-3, 3rd edn. Cold Spring Harbor, NY: Cold Spring Harbor Laboratory Press; 2001.

162. Cresnar B, Mages W, Müller K, Salbaum JM, Schmitt R: Structure and expression of a single actin gene in Volvox carteri. Curr Genet 1990, 18(4):337-346.

163. Bustin SA: Absolute quantification of mRNA using real-time reverse transcription polymerase chain reaction assays. J Mol Endocrinol 2000, 25(2):169-193.

164. Pfaffl MW: A new mathematical model for relative quantification in real-time RT-PCR. Nucleic Acids Res 2001, 29(9):e45.

\section{doi:10.1186/1471-2164-15-1117}

Cite this article as: Kianianmomeni et al:: Genome-wide analysis of alternative splicing in Volvox carteri. BMC Genomics 2014 15:1117.

\section{Submit your next manuscript to BioMed Central and take full advantage of:}

- Convenient online submission

- Thorough peer review

- No space constraints or color figure charges

- Immediate publication on acceptance

- Inclusion in PubMed, CAS, Scopus and Google Scholar

- Research which is freely available for redistribution 